Brazilian Journal

of Chemical

Engineering

\title{
PRELIMINARY ASSESSMENT OF THE PROCESSING OF HIGH-ACIDITY FATTY MATERIALS USING SOLID CATALYSTS FOR THE OBTAINMENT OF FATTY ACID METHYL ESTERS
}

\author{
Luis R. S. Kanda ${ }^{1}$, Fabiane Hamerski ${ }^{1}$, Marcos L. Corazza ${ }^{1 *}$ and Fernando Wypych ${ }^{2}$ \\ ${ }^{1}$ Universidade Federal do Paraná, Departamento de Engenharia Química, Curitiba, PR, Brazil. E-mail: 1rkanda@yahoo.com.br; \\ E-mail: fabianehamerski@ufpr.br; E-mail: corazza@ufpr.br \\ ${ }^{2}$ Universidade Federal do Paraná, Departamento de Química, Curitiba, PR, Brazil. E-mail: wypych@ufpr.br
}

(Submitted: February 23, 2019 ; Revised: June 24, 2019 ; Accepted: June 26, 2019)

\begin{abstract}
This work presents the processing of a high-acidity oil through sequential reactions of esterification using montmorillonite K10 and transesterification using zinc monoglycerolate. Since these solids had not been employed along with this approach beforehand, the objective of this work is to provide a general insight of the proposed process and demonstrate its technical feasibility. In this sense, the processing of a synthetic mixture containing soybean oil and lauric acid provided a reduction of the free fatty acid content from $(40.8 \pm 0.1) \%$ to $(3.1 \pm 0.4) \%$ after the esterification reaction and a fatty acid methyl ester yield of $(95.4 \pm 0.2) \%$ was obtained after the transesterification reaction. As compared to traditional homogeneous catalysts, the solid catalysts employed in this work require higher reaction times to achieve satisfactory ester yields but, on the other hand, they are less sensitive to the presence of both water and free fatty acids in the raw materials and can be easily recovered and reused. Therefore, the results accomplished may help the development of a technology for processing high-acidity fatty materials in order to obtain biodiesel, although its economic feasibility still needs a further assessment. Keywords: Biodiesel; Acid oil; Esterification; Montmorillonite K10; Transesterification; Zinc monglycerolate.
\end{abstract}

\section{INTRODUCTION}

Biodiesel is often more expensive than diesel fuel and the main reason is the high cost of the raw materials, which may correspond to up to $88 \%$ of the biodiesel cost (Haas, 2005). Furthermore, there is an increasing concern about food security, since the commonly used raw materials can generate a competition with the food industry (Koizumi, 2015). In this scenario, residual fatty materials draw attention due to their low cost and also because their processing might result in an environmental gain, even though these materials may contain high amounts of free fatty acids (FFA).

Throughout the refining processes of vegetable oils, several streams with different FFA contents are generated, and these values also depend on the vegetable source. Piloto-Rodriguez et al. (2014) reported the content of both FFA and triacylglycerol present in each of these fractions, named distilled fatty acids, soapstock and acid oil. In what concerns the refining of soybean oil, the FFA contents of these streams are around $40 \%$ for the distilled fatty acids (Piloto-Rodríguez et al., 2014), while ranging between $35 \%$ and $50 \%$ for the soapstock, and are up to 60 $\%$ for the acid oil obtained through the acidification of the soapstock (Piloto-Rodríguez et al., 2014; Wang et al., 2007). Other interesting residual fatty materials are waste cooking oils, whose FFA contents are around $3.5 \%$ (Otadi et al., 2011), and a lipid-rich waste material obtained from sewage sludge, whose FFA

\footnotetext{
* Corresponding author: Marcos Lucio Corazza - E-mail: corazza@ufpr.br
} 
contents vary from around $15 \%$ (Kwon et al., 2012) to values between $60 \%$ and $70 \%$ (Boocock et al., 1992; Olkiewicz et al., 2016).

For the use of conventional transesterification reaction catalysts, such as metal hydroxides or alkoxides, it is preferable that the FFA contents of raw materials are lower than $0.5 \%$ (or $1 \mathrm{mg} \mathrm{KOH} \cdot \mathrm{g}^{-1}$ ), although it is possible to achieve the processing of raw materials whose FFA contents are up to $5 \%$ (Canakci and Gerpen, 2001; Mittelbach and Remschmidt, 2005). Nevertheless, it may be necessary to perform the neutralization of FFA, either by the addition of a glycerol-rich phase of a previous batch (which contains the alkaline catalyst), or by the FFA removal by distillation at high temperatures (Mittelbach and Remschmidt, 2005). Another option is to perform an esterification reaction, in which the FFA are converted to esters, but in this case the proper catalyst is sulfuric acid (Almeida et al., 2015; Encinar et al., 2011; Marchetti et al., 2011).

The aforementioned catalysts (metal hydroxides or alkoxides for transesterification reactions and sulfuric acid for esterification reactions) allow the obtainment of high ester yields, under mild reaction conditions, and require relatively low reaction times. However, the main disadvantage of their use is the difficulty of recovery for further reuse, in such a way that they must be removed from the final product through several washing steps, which also increase production costs and generate more liquid wastes (Mittelbach and Remschmidt, 2005).

On the other hand, solid catalysts have as an advantage the possibility of being easily recovered and reused in the process, while the main disadvantage is the slower reaction rate, thus requiring higher temperatures to achieve satisfactory ester yields. Moreover, solid catalysts are not as sensitive to the characteristics of poor quality raw materials as metal alkoxides or hydroxides and are not as corrosive as sulfuric acid (Mittelbach and Remschmidt, 2005). Therefore, research on alternative solid catalysts capable of processing poor-quality raw materials for biodiesel production could enable the reduction of costs of both raw materials and process operations, whilst the final product still meets the specifications required (Mendow et al., 2011).

In this context, mixed oxides, other mixed compounds (Jindapon et al., 2016), sulfated oxides (Istadi et al., 2015), zincates (Rubio-Caballero et al.,
2009), and magnetic catalysts (Dantas et al., 2017) have been reported for the processing of vegetable oils and animal fats with low acid contents (Dias et al., 2012; Pasupulety et al., 2015). Other authors employed solid catalysts for the processing of raw materials with high FFA contents, such as sulfonated solids, used in reactions with materials containing FFA contents of $10 \%$ (Fadhil et al., 2016), $15 \%$ (Dawodu et al., 2014) and up to $43.73 \%$ (Konwar et al., 2014), and bifunctional catalysts with both Brönsted and Lewis acid sites, used for the processing of materials with FFA contents of $1.78 \%$ (Pan et al., 2018) and from $8.6 \%$ to $60 \%$ (Wang et al., 2017). Other solid catalysts such as zeolites, heteropolyacids and metal oxides have also been used, as mentioned in the review presented by Mansir et al. (2017). Finally, zinc monoglycerolate (ZnMGly), used in this work as catalyst for transesterification reactions, also presented catalytic activity regarding the processing of raw materials containing $10 \%$ of FFA (Kwong and Yung, 2016) or even the esterification of oleic acid until a certain extent (Reinoso et al., 2014).

Hence, the main objective of this work was to provide a primary assessment of the processing of high-acidity oils using solid catalysts to obtain high contents of fatty acid methyl esters (FAME). Therefore, an approach consisting of two units with different main reactions (esterification and transesterification), represented by the block diagram shown in Fig. 1, was chosen and its technical feasibility was evaluated. Each unit has unique features, concerning the catalysts, raw materials, reactional conditions (temperature, pressure, density, viscosity, etc) and purification operations. For the development of this strategy, two solid catalysts with known catalytic activity were selected and retested under reaction conditions which were different than those already presented in the literature (Lisboa et al., 2014; Lisboa et al., 2013; Reinoso et al., 2014; Zatta et al., 2013).

Montmorillonite K10 was selected as catalyst for esterification reactions, since activated clay minerals, in general, can be very interesting catalysts for esterification reactions, as reported by several authors (Kanda et al., 2017; Neji et al., 2011; Neji et al., 2009; Pires et al., 2013; Rezende et al., 2012; Santos et al., 2016; Zatta et al., 2012a; Zatta et al., 2012b; Zatta et al., 2011). Furthermore, reports in the literature about the use of this catalyst for the processing of highacidity oils are scarce. This solid is supplied by the

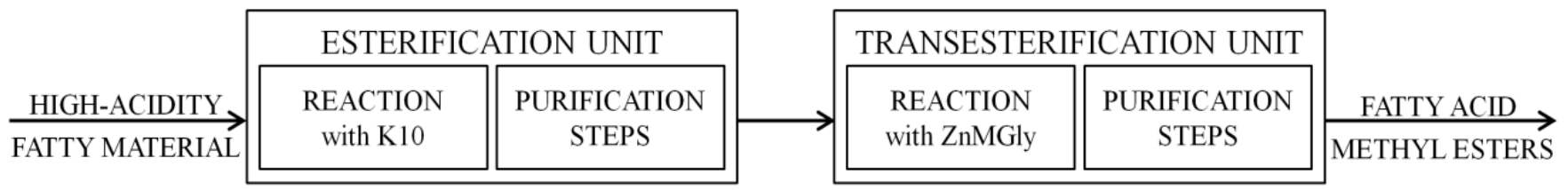

Figure 1. Block diagram for the high-acidity fatty material processing. 
manufacturer after acid and thermal activation of the montomorillonite clay mineral, resulting in a highsurface area material containing strong Brönsted and Lewis acid sites.

Additionally, the catalyst chosen for the transesterification reaction was zinc monoglycerolate, mainly because of its thermal stability, which allowed the use of this solid at higher temperatures than those employed by other authors (Lisboa et al., 2013; Reinoso et al., 2014), so as to improve the reaction evolution. The use of glycerolates (also named glyceroxides) has a close relationship with the use of oxides, since they are formed in situ during transesterification reactions due to the presence of glycerol (Kouzu et al., 2009; León-Reina et al., 2013; López Granados et al., 2010). Several authors employed calcium diglycerolate for transesterification reactions, among them Lukic et al. (2016), who also presented a review about the use of this solid (as well as calcium monoglycerolate) as catalyst towards these reactions. Other works reported the use of different metal glycerolates as catalysts for biodiesel production, such as glycerolates of potassium (Pradhan et al., 2017), lithium (Wang et al., 2015), manganese, iron, cobalt (Lau et al., 2016), calcium, strontium, barium (Lisboa et al., 2014) and zinc (Lau et al., 2016; Lisboa et al., 2014; Reinoso et al., 2014).

The reaction conditions chosen to perform this study are slightly different than those reported in previous works (Lisboa et al., 2014; Lisboa et al., 2013; Reinoso et al., 2014; Zatta et al., 2013), mainly considering the temperature range. The first block of experiments is related to the study of each reaction, while the second block is related to the processing of acid oil (FFA contents of nearly $40 \%$ ) through the coupled reactions. It is worth mentioning that an industrial process could use buffer tanks to help and adequate the acidity of the raw material to the desired range of values, avoiding oscillation and easing the reactor operation.

\section{MATERIALS AND METHODS}

\section{Chemicals}

Esterification studies were performed using montmorillonite K10 (Sigma-Aldrich, CAS number 1318-93-0) and lauric acid (Sigma-Aldrich, $\geq 98 \%$, CAS number 143-07-7), while transesterification reactions used refined soybean oil (Coamo) and zinc monoglycerolate previously synthesized using zinc acetate dihydrate (Sigma-Aldrich, $\geq 98 \%$, CAS number 5970-45-6) and glycerol (Synth, $\geq 99 \%$, CAS number 56-81-5), while its further purification was performed through washing steps using decarbonated distilled water and anhydrous ethanol (Neon, $\geq 99.5$ $\%$, CAS number 64-17-5). Methanol (Neon, $\geq 99.8 \%$, CAS number 67-56-1) was employed as the short chain alcohol for both esterification and transesterification reactions and anhydrous sodium sulfate (Vetec, $\geq 99 \%$, CAS number 7757-82-6) was used in the purification steps of the final products obtained.

Titration analysis was carried out using hydrated ethanol (Neon, $\geq 95.0 \%$, CAS number 64-17-5), sodium hydroxide (Vetec, $\geq 97 \%$, CAS number 1310-73-2), potassium biphthalate (Vetec, $\geq 99.5$ $\%$, CAS number 877-24-7) and phenolphthalein (Sigma-Aldrich, CAS number 77-09-8) as indicator. The gas chromatography was performed using the derivatization agent MSTFA ( $N$-methyl- $N$ (trimethylsilyl) trifluoroacetamide, Sigma-Aldrich, $\geq$ 98.5\%, CAS number 24589-78-4), heptane (Sigma Aldrich, $\geq 99 \%$, CAS number 142-82-5) and the internal standards ethyl palmitate (Sigma Aldrich, $\geq$ 98.5\%, CAS number 628-97-7 67107) and tricaprin (Supelco, solution $8 \mathrm{mg} \mathrm{mL}^{-1}$, CAS number 621-716). The calibration curves were obtained using methyl linoleate (Sigma-Aldrich, $\geq 98.5 \%$, CAS number 11263-0), monoolein (Supelco, solution $5 \mathrm{mg} \mathrm{mL}^{-1}$, CAS number 111-03-5), diolein (Supelco, solution $5 \mathrm{mg}$ $\mathrm{mL}^{-1}$, CAS number 2465-32-9) and triolein (Supelco, solution $5 \mathrm{mg} \mathrm{mL}^{-1}$, CAS number 122-32-7).

All chemicals were used without any further purification.

\section{Zinc monoglycerolate synthesis and characterization}

Zinc monoglycerolate was synthesized following the reaction presented in Eq. (1), using the glycerol reflux method, as employed by Dong and Feldmann (2012). The experimental apparatus was composed of a hot plate stirrer, which provided both the heating and the magnetic stirring, and a three-neck flask as the reactor. The reactor was kept under nitrogen flow along the course of the reaction, so as to remove the other reaction product, acetic acid, and avoid zinc monoglycerolate consumption, since it is a reversible reaction.

$$
\begin{aligned}
& 1\left(\mathrm{CH}_{3} \mathrm{COO}\right)_{2} \mathrm{Zn}+1 \mathrm{C}_{3} \mathrm{H}_{8} \mathrm{O}_{3} \rightleftarrows \quad 1 \mathrm{C}_{3} \mathrm{H}_{6} \mathrm{O}_{3} \mathrm{Zn}+2 \mathrm{CH}_{3} \mathrm{COOH} \\
& \text { (zinc aectate) (glycerol) (zinc monoglycerolate) (acetic acid) }
\end{aligned}
$$

After the reaction, the solid was purified by a threestep washing procedure, the first using decarbonated distilled water and the two remaining using ethanol. The solids were vigourosly stirred with the solvents and immediatly centrifuged at $4500 \mathrm{rpm}(\sim 3600 \mathrm{~g})$ for $10 \mathrm{~min}$. Following the washing steps, the solid was dried in a vacuum oven at $60{ }^{\circ} \mathrm{C}$ for $24 \mathrm{~h}$ and kept under the form of a fine powder for its characterization through the following analyses: X-Ray Diffraction (XRD), Fourier Transform Infrared Spectroscopy (FTIR), Scanning Electron Microscopy (SEM) and Thermogravimetric Analysis (TGA/DTG). 
XRD analyses were performed using a Shimadzu, XRD-7000, X-Ray diffractometer, which uses $\mathrm{Cu}_{\mathrm{k} \alpha}$ radiation $(1.5418 \AA)$, in the range from $3^{\circ}$ to $40^{\circ}(2 \theta)$, step of $0.02^{\circ}$, scanning speed of $2^{\circ} \mathrm{min}^{-1}$, voltage of $40 \mathrm{kV}$ and current of $20 \mathrm{~mA}$. FTIR analyses were performed using a Bomem spectrometer, model MB100, ranging from $4000 \mathrm{~cm}^{-1}$ to $400 \mathrm{~cm}^{-1}$, with $4 \mathrm{~cm}^{-1}$ of resolution, using transmission mode with accumulation of 32 scans. SEM analysis was performed using a Tescan microscope, model Vega LMU, with resolution of $3 \mathrm{~nm}$. TGA/DTG analysis was performed using a Perkin-Elmer equipment, model TGA 4000, using circa $10 \mathrm{mg}$ of sample, synthetic air flowing at $50 \mathrm{~mL} \mathrm{~min}^{-1}$ and using a heating rate of $10{ }^{\circ} \mathrm{C} \mathrm{min}^{-1}$, from $30{ }^{\circ} \mathrm{C}$ to $1000{ }^{\circ} \mathrm{C}$.

\section{Catalytic tests}

The catalytic tests were performed using a $300 \mathrm{~mL}$ Parr bench top mini reactor (series 4560), whose scheme is presented in Fig. 2, equipped with an electrical heater attached to a controller, in order to keep the temperature of the reaction media at the desired value. The controller also permitted setting the stirring speed and a pressure gauge attached to the reactor helped to monitor the pressure. A sampling system allowed the withdrawal of samples from inside of the reactor and the procedure was explained in details in a previous work of our research group (Kanda et al., 2017). In summary, it consisted of a tube extending near to the bottom of the reaction vessel, which allowed the sampling at chosen times of the reaction using a manually operated needle valve.

As for the reaction conditions, the ranges of values were set in agreement with those of previous works (Kanda et al., 2017; Lisboa et al., 2013; Zatta et al., 2013) (even though the study by Kanda et al. (2017) was performed using ethanol, which is less reactive

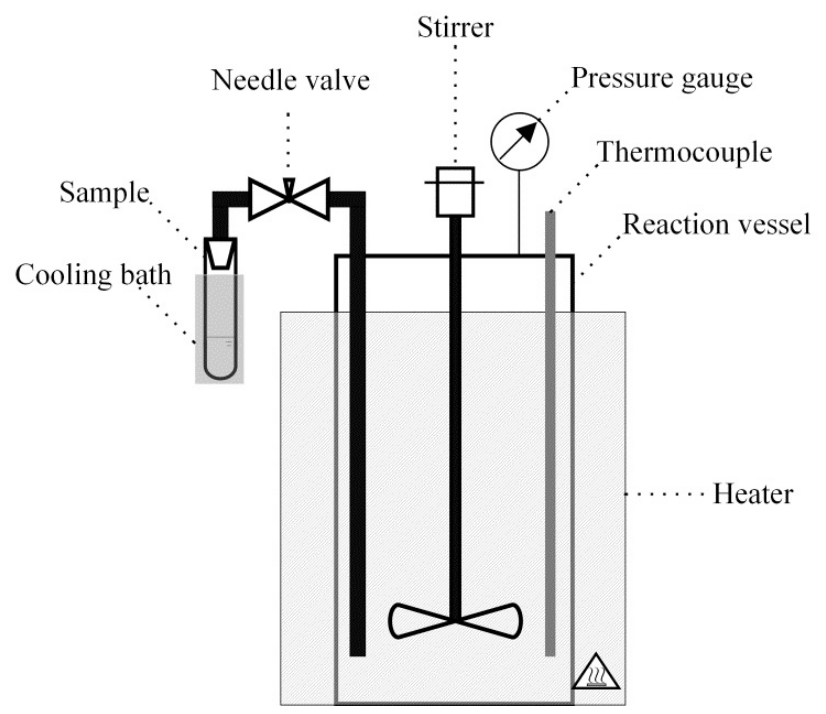

Figure 2. Experimental set-up used in this work. than methanol). The stirring speed was fixed at 500 $\mathrm{rpm}$ for all the reactions, since this was demonstrated to be the optimum value (Lisboa et al., 2013; Zatta et al., 2013). Both esterification and transesterification reactions were also performed in the absence of catalysts, in order to assess the effective contribution of the catalysts.

The initial time of reaction $(t=0)$ was set as the moment when the reaction heating was turned on. The first sample was withdrawn from the reactor as soon as the temperature reached the desired value, while the other samples were withdrawn at times of reaction that were chosen according to the type of reaction. The maximum number of samples was 6 , so the amount removed from the reactor did not have an impact on the reaction evolution.

After sampling, the catalysts were separated by centrifugation at $3500 \mathrm{rpm}$ for $10 \mathrm{~min}$ and the alcohol was removed by evaporation at $50{ }^{\circ} \mathrm{C}$ using an air-circulation oven at atmospheric pressure inside of which the samples were left for $24 \mathrm{~h}$. After this treatment, the samples were analyzed properly, by titration with $\mathrm{NaOH}$ for the determination of FFA content and/or by gas chromatography to evaluate the contents of fatty acid methyl esters (FAME), monoacylglycerols (MAG), diacylglycerols (DAG), and triacylglycerols (TAG).

Since zinc monoglycerolate undergoes a series of transformations in the presence of a considerable amount of free fatty acids, resulting in the formation of zinc carboxylate (Reinoso et al., 2014), it was decided that this catalyst would not be tested for high values of FFA contents. Nevertheless, it was still necessary to determine the integrity of this solid after the reactions, which was achieved through XRD, FTIR and TGA analyses of the recovered solids. The degradation of zinc monoglycerolate could be verified by the presence of either zinc oxide, as a result of oxidation reactions, or zinc carboxylates, as a result of the reaction between zinc monoglycerolate and FFA.

\section{Purification steps}

The samples obtained during the reactions for the acid oil processing were prepared prior to the analyses as described earlier. However, after the last sampling of each reaction, the whole content of the reactor was subjected to purification steps which were performed according to the type of reaction, in order to remove not only the catalysts, but also by-products and, consequently, the alcohol.

At the end of the esterification reaction, the reaction medium was cooled down by the flow of fresh water through a cooling coil positioned inside the reactor, which did not allow direct contact between the hot and cold fluids, in a process that lasted around 25 min. Then, the whole content was withdrawn from 
the reactor and left to rest for at least $12 \mathrm{~h}$ to enable the catalyst to settle down. After the catalyst removal, methanol was separated by vacuum distillation and the non-volatile phase was again left to rest to assure that an insignificant amount of montmorillonite K10 would be present during the transesterification step.

As for the transesterification reaction, the same procedure for the cooling of the reaction medium was followed after the reaction was over, but the methanol removal was performed prior to the catalyst separation, since its presence appeared to limit the settling of the catalyst. After methanol removal, the occurrence of a liquid-liquid phase separation was possible, in which both glycerol and zinc monoglycerolate remained in the bottom phase. The upper phase, composed mainly of the methyl esters formed, was separated and washed three times with warm distilled water $\left(60^{\circ} \mathrm{C}\right)$ to ensure glycerol traces were removed and then filtered using anhydrous sodium sulfate.

\section{FFA content analysis}

The FFA content was obtained using a method presented by Rukunudin et al. (1998), adapted from the AOCS 5a-40 method. This method shows good agreement with results obtained by high-performance liquid chromatography (HPLC) (Cordeiro et al., 2012) and nuclear magnetic resonance (NMR) (Zatta et al., 2012a) and was used in several works (Cordeiro et al., 2012; Kanda et al., 2017; Santos et al., 2016; Zatta et al., 2012a). The procedure consists of the titration of the samples with a sodium hydroxide solution $(0.1$ mol $\left.\mathrm{L}^{-1}\right)$, previously standardized with potassium biphthalate. The FFA content was determined in duplicate using Eq. (2), adapted from the literature (Rukunudin et al., 1998):

$$
\text { FFA Content }(\%)=100 \cdot \frac{\mathrm{M} \cdot \mathrm{V} \cdot \mathrm{f} \cdot \mathrm{C}}{\mathrm{m}}
$$

where $\mathrm{M}$ is the molar mass of the free fatty acid ( $\mathrm{g}$ $\left.\mathrm{mol}^{-1}\right), \mathrm{V}$ is the volume of the $\mathrm{NaOH}$ solution used in the procedure $(\mathrm{L}), \mathrm{f}$ is a correction factor for the $\mathrm{NaOH}$ solution (dimensionless), $\mathrm{C}$ is the molar concentration of the $\mathrm{NaOH}$ solution $\left(\mathrm{mol} \mathrm{L}^{-1}\right)$, and $\mathrm{m}$ is the mass of the sample $(\mathrm{g})$.

The conversions were calculated by the comparison of the FFA content of the raw material before the esterification reaction and that of the samples analyzed, according to Eq. (3):

$$
\mathrm{X}_{\mathrm{FFA}}(\%)=100 \cdot \frac{\left(\mathrm{FFA}_{0}-\mathrm{FFA}_{\mathrm{i}}\right)}{\mathrm{FFA}_{0}}
$$

where $\mathrm{X}_{\mathrm{FFA}}$ is the FFA conversion (\%), FFA is the FFA content before the esterification reaction (\%) and FFA is the FFA content of the samples analyzed (\%).

\section{Gas chromatography analysis}

For this analysis a Shimadzu gas chromatograph (model GC 2010 Plus) with a flame ionization detector (FID) was used. The chromatograph was equipped with a Select Biodiesel column (Agilent, $15 \mathrm{~m}$ x 0.32 $\mathrm{mm} \times 0.10 \mu \mathrm{m})$ with split injection mode $(1: 10)$. Temperatures of the injector and the detector were set to $380{ }^{\circ} \mathrm{C}$ and $400{ }^{\circ} \mathrm{C}$, respectively. The initial oven temperature was set to $50{ }^{\circ} \mathrm{C}$ and the temperature heating rate was programmed at $15{ }^{\circ} \mathrm{C} \mathrm{min}^{-1}$ until $180{ }^{\circ} \mathrm{C}, 7{ }^{\circ} \mathrm{C}$ min $^{-1}$ until $230{ }^{\circ} \mathrm{C}$ and $10{ }^{\circ} \mathrm{C}$ min $^{-1}$ until $380{ }^{\circ} \mathrm{C}$, remaining at this temperature for $6 \mathrm{~min}$. Helium was used as carrier gas at a flow rate of 29.2 $\mathrm{cm}^{3} \mathrm{~min}^{-1}$.

The samples to be analyzed were first diluted in appropriate amounts of heptane or ethanol and a small amount of this solution was added to a vial, as well as the solution containing the internal standards (ethyl palmitate and tricaprine) and the derivatization reagent MSTFA. The final required volume was reached by the addition of heptane so that the solutions analyzed by $\mathrm{GC}$ had concentrations near to $1 \mathrm{mg} \mathrm{mL}^{-1}$. Despite both the injection mode and the injector temperature, this procedure was based in the recommendations of the standards for quantification of FAME (EN 14103) and acylglycerols (EN 14105), in which calibration curves for the species were provided using methyl linoleate, monoolein, diolein and triolein.

The results are presented as content (mass fractions) of compounds versus time of reaction, but for comparison purposes, the processing of acid oils was evaluated through TAG conversion $\left(\mathrm{X}_{\mathrm{TAG}}\right)$ and FAME yield $\left(\mathrm{y}_{\mathrm{FAME}}\right)$, calculated using Eqs. (4) and (5), along with the FFA conversion $\left(\mathrm{X}_{\mathrm{FFA}}\right)$, defined previously by Eq. (3):

$$
\begin{aligned}
& \mathrm{X}_{\mathrm{TAG}}(\%)=100 \cdot \frac{\left(\mathrm{TAG}_{0}-\mathrm{TAG}_{\mathrm{i}}\right)}{\mathrm{TAG}_{0}} \\
& \mathrm{y}_{\mathrm{FAME}}(\%)=100 \cdot \frac{\mathrm{FAME}_{\mathrm{i}}}{\left(3 \cdot \mathrm{TAG}_{0}+2 \cdot \mathrm{DAG}_{0}+\mathrm{MAG}_{0}+\mathrm{FFA}_{0}\right)}
\end{aligned}
$$

where $\mathrm{X}_{\mathrm{TAG}}$ is the TAG conversion (\%), $\mathrm{y}_{\mathrm{FAME}}$ is the FAME yield (\%), TAG $, \mathrm{DAG}_{0}, \mathrm{MAG}_{0}$ and $\mathrm{FFA}_{0}$ are the initial number of moles of TAG, DAG, MAG and FFA, respectively, and TAG and FAME are the number of moles of TAG and FAME, respectively, of the samples analyzed.

\section{RESULTS AND DISCUSSION}

\section{Catalyst characterization}

An extensive characterization of the as-received montmorillonite K10 was reported in a previous work from our research group (Kanda et al., 2017), including 
XRD and FTIR analyses, as well as information regarding the acidic sites and textural properties. The material was not analyzed after the reactions performed in this work, since acid activated clay minerals tend to be stable compounds that can be reused for several reaction cycles (Santos et al., 2016; Zatta et al., 2013; Zatta et al., 2012a).

As for the zinc monoglycerolate, Lisboa et al. (2013) reported the possibility that this catalyst could be reused three times, while Reinoso et al. (2014) performed five catalytic cycles with this solid without its deactivation. In this work, three different batches were prepared and after the X-Ray Diffraction (XRD) analysis confirmed the formation of the desired compound, as shown in Fig. A.1 (Appendix), the batches were mixed together. The reaction conditions are presented in Table 1 and the time of reaction was fixed at $2 \mathrm{~h}$. Therefore, the zinc glycerolate used for the transesterification reactions was composed of the solids of these three batches, whose mass percentages were $85.5 \%$ of batch $\# 1,7.7 \%$ of batch $\# 2$ and $6.8 \%$ of batch \#3.

The Bragg's Law equation was used to determine the basal distance, which for batch \#1 was $8.10 \AA$, as identified by the basal peak around $10.92^{\circ}(2 \theta)$, while these values for batch $\# 2$ were $8.05 \AA$ and $10.99^{\circ}(2 \theta)$ and, for batch \#3, $8.03 \AA$ and $11.01^{\circ}(2 \theta)$, respectively. These results are nearly identical to the values reported by Lisboa et al. (2013). The main peaks observed for the XRD pattern of zinc monoglycerolate crystals are around $10^{\circ}(100), 17^{\circ}(011), 20^{\circ}(111)$ and $28^{\circ}(211)$ $\left(2 \theta, \mathrm{Cu}_{\mathrm{kc}}\right.$ radiation).

Batches \#2 and \#3 were obtained after an attempt to perform the synthesis of supported zinc monoglycerolate using different types of silica supports (these solids were obtained as a residue, outside the supports). SEM analysis, presented in Figs. 3.A-D, confirmed the platelet-like morphology of the zinc monoglycerolate particles obtained, which is typical of layered materials and was also observed by Reinoso et al. (2014). However, the dimensions varied according to the conditions used during each synthesis and, as a result of the mixture of different batches, the SEM image of batch \#4 (Fig. 3.D) indicated the presence of heterogeneous particle sizes. As long as this batch was used for all the transesterification reactions, including those performed for the acid oil

Table 1. Reaction conditions used for the synthesis of zinc monoglycerolate.

\begin{tabular}{ccc}
\hline Batch \# & MR & T $\left({ }^{\circ} \mathbf{C}\right)$ \\
\hline 1 & 46 & $109-119$ \\
2 & $29^{\mathrm{a}}$ & $85-93$ \\
3 & $30^{\mathrm{a}}$ & $97-101$ \\
$4^{\mathrm{b}}$ & - & -
\end{tabular}

MR = Molar Ratio glycerol:zinc acetate.

a Theoretical values. The pore volume of the silica supports might have restricted the access of glycerol to the zinc acetate impregnated inside the pores.

b Obtained by blending batches \#1, \#2 and \#3
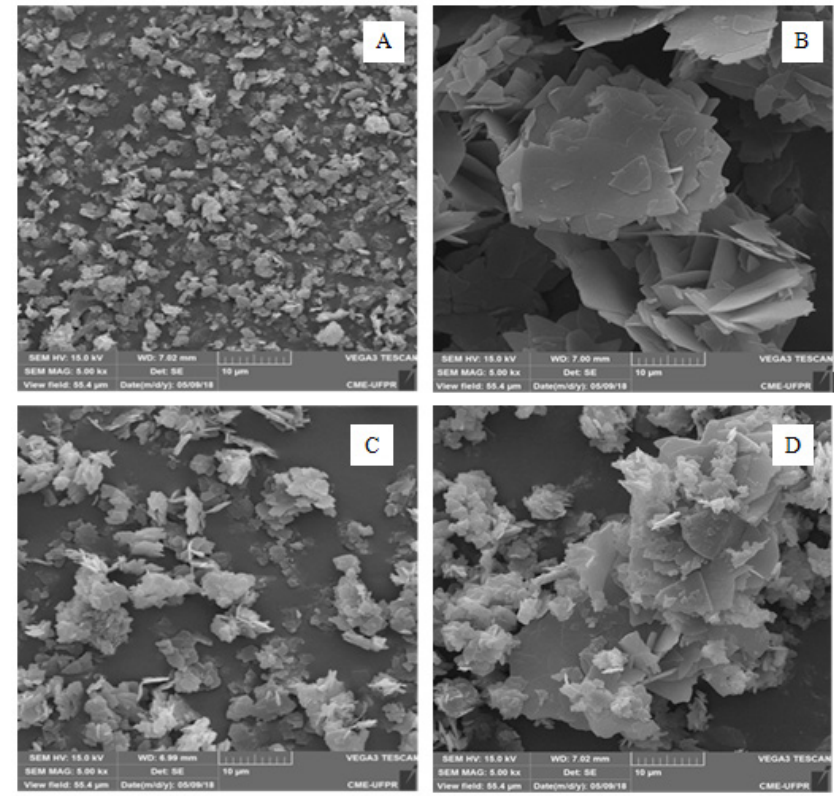

Figure 3. SEM images of zinc monoglycerolate: (A) batch \#1, (B) batch \#2, (C) batch \#3, and (D) batch \#4.

processing, the comparison of the obtained results was not affected by this feature.

Moreover, batch \#1 was analyzed by FTIR (this analysis will be further presented) and batch \#4 was analyzed by TGA (Fig. A.2 - Appendix), confirming the formation of the desired compound. According to the thermal analysis, the first thermal event, related to water removal (dehydration), presented an onset temperature of $110{ }^{\circ} \mathrm{C}$ and $1^{\text {st }}$ derivative peak temperature of $135{ }^{\circ} \mathrm{C}$, resulting in a mass loss of $6.0 \%$ (which can be attributed to the humidity of the material). The second thermal event, related to the zinc monoglycerolate oxidation to zinc oxide, presented an onset temperature of $360{ }^{\circ} \mathrm{C}$ and $1^{\text {st }}$ derivative peak temperature of $375{ }^{\circ} \mathrm{C}$. The amount of zinc oxide obtained at the end of the analysis corresponded to $50.3 \%$ of the initial mass, on a dry basis. This result is very close to the theoretical value expected for zinc monoglycerolate $\left(\mathrm{Zn}\left(\mathrm{C}_{3} \mathrm{H}_{6} \mathrm{O}_{3}\right)\right)$, which is $52.3 \%$ (deviation of $3.8 \%$ ).

\section{Methyl esterification of lauric acid}

The reaction conditions employed in the assessment of lauric acid esterification using methanol and montmorillonite $\mathrm{K} 10$ as catalyst are presented in Table 2 and were chosen as such due to the achievement of the best results, as reported by Kanda et al. (2017) for the ethylic route. In this study, 6 esterification reactions were performed and each reaction provided 6 samples, resulting in a total of 36 experimental data. In this case, the molar ratio (MR) is referred to the number of moles of methanol for each mole of FFA, while the catalyst load (Cat.) represents the mass of montmorillonite K10 used for each $100 \mathrm{~g}$ of FFA. 
The results obtained are presented in terms of FFA conversion versus time of reaction in Fig. 4. It is possible to infer that the reaction may occur if enough heat is provided to the system, although the catalyst was responsible for improving the reaction rates. For all cases, the maximum time of reaction evaluated was $6 \mathrm{~h}$ and the higher conversion obtained for reactions performed without catalyst was $90.6 \%$ at $180{ }^{\circ} \mathrm{C}$. As for the montmorillonite $\mathrm{K} 10$-catalyzed reactions, at $140{ }^{\circ} \mathrm{C}$ the FFA conversion was $95.0 \%$ after $6 \mathrm{~h}$, while at $160{ }^{\circ} \mathrm{C}$ the conversion reached $95.4 \%$ after $90 \mathrm{~min}$ and at $180{ }^{\circ} \mathrm{C}$, the conversion reached $95.0 \%$ after $60 \mathrm{~min}$. These values around $95 \%$ seem to refer to the equilibrium conversion, since it was not possible to achieve higher conversions, even for longer reaction times.

The effect of molar ratio on the methyl esterification of lauric acid catalyzed by montmorillonite $\mathrm{K} 10$ was evaluated for reactions performed at $180{ }^{\circ} \mathrm{C}$. The amount of catalyst is usually reported as the relation between the mass of catalyst and the mass of FFA. However, since the volume of the reaction medium

Table 2. Experimental conditions employed in the methyl esterification of lauric acid catalyzed by montmorillonite K10.

\begin{tabular}{cccc}
\hline Reaction & T $\left({ }^{\circ} \mathbf{C}\right)$ & MR & Cat. (\%) \\
\hline E1 & 140 & $6.06: 1$ & 12.03 \\
E2 & 160 & $6.18: 1$ & 12.01 \\
E3 & 180 & $5.97: 1$ & 11.75 \\
E4 & 140 & $6.01: 1$ & 0 \\
E5 & 160 & $6.10: 1$ & 0 \\
E6 & 180 & $6.01: 1$ & 0 \\
\hline
\end{tabular}

$\mathrm{MR}=$ Molar Ratio methanol:lauric acid; Cat. $=$ Catalyst load expressed as $\mathrm{g}$ of catalyst per $100 \mathrm{~g}$ of lauric acid.

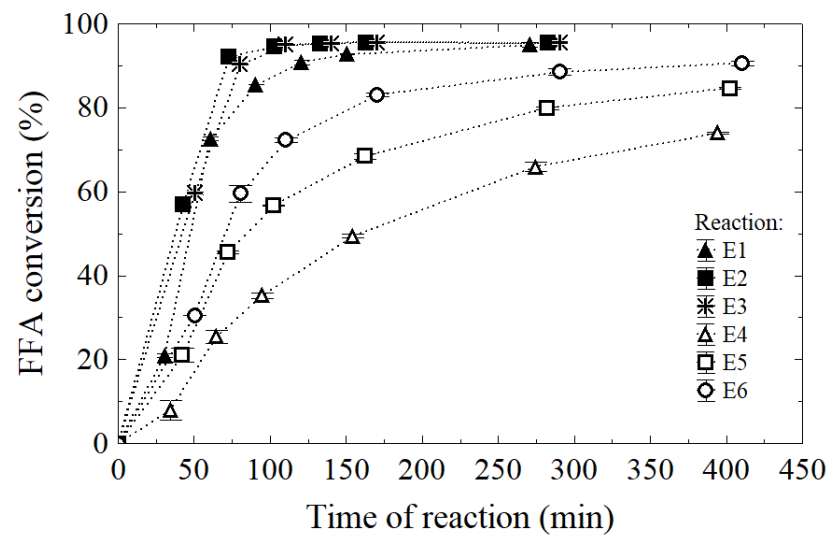

Figure 4. Comparison of the results obtained for the methyl esterification of lauric acid (Cat. $\approx 12 \%$ and $\mathrm{MR} \approx 6: 1)$. Symbols represent experimental data obtained for reactions without catalyst (empty symbols) and using montmorillonite K10 (full symbols and asterisk), at $\mathrm{T}=140{ }^{\circ} \mathrm{C}$ (triangles, $\mathrm{E} 1$ and $\left.\mathrm{E} 4\right), \mathrm{T}=$ $160{ }^{\circ} \mathrm{C}$ (squares, E2 and E5) and $\mathrm{T}=180{ }^{\circ} \mathrm{C}$ (asterisks and circles, E3 and E6). Dotted lines are a guide for the eye. was required to be kept in a certain range (so that the samples withdrawn from the reaction vessel did not interfere in the results), when different molar ratios are tested, the amount of FFA also varies, which affects the amount of catalyst. Therefore, to avoid the catalyst dilution, its concentration was kept constant and is reported as $g$ of catalyst per $\mathrm{L}$ of reaction media.

The reaction conditions are presented in Table 3 , while the results obtained, presented in Fig. 5, allowed the observation of the equilibrium conversion displacement due to the use of excess alcohol. Using a MR methanol:FFA near to 3:1, the conversion could not exceed $91.8 \%$, while for MR near to $6: 1$ and higher (the other values tested in this work were around 12:1 and 50:1), maximum values are around $95 \%$ and cannot be surpassed. On the other hand, the equilibrium was reached faster when higher amounts of methanol were used. Under the conditions tested in this work $\left(\mathrm{T}=180^{\circ} \mathrm{C}\right.$ and Cat. $\left.\approx 40 \mathrm{~g} \mathrm{~L}^{-1}\right)$, all MR except near 3:1 provided nearly the same values of conversion after $30 \mathrm{~min}$ of reaction (or around $75 \mathrm{~min}$, if the heating of the reaction media is considered).

Due to the experimental set-up, the reagents must be loaded into the reaction vessel at room temperatures and the reaction media is heated to the desired temperature using a heating mantle (electrical

Table 3. Experimental conditions employed to evaluate the effect of molar ratio on the methyl esterification of lauric acid catalyzed by montmorillonite K10.

\begin{tabular}{cccc}
\hline Reaction & T $\left({ }^{\circ} \mathbf{C}\right)$ & MR & Cat. $\left(\mathbf{g ~ L}^{-1}\right)$ \\
\hline E7 & 180 & 3.05 & 39.7 \\
E8 & 180 & 5.97 & 40.7 \\
E9 & 180 & 11.94 & 40.3 \\
E10 & 180 & 49.79 & 39.8 \\
\hline
\end{tabular}

MR = Molar Ratio methanol:lauric acid; Cat. = Catalyst load expressed as g of catalyst per liter of reaction media.

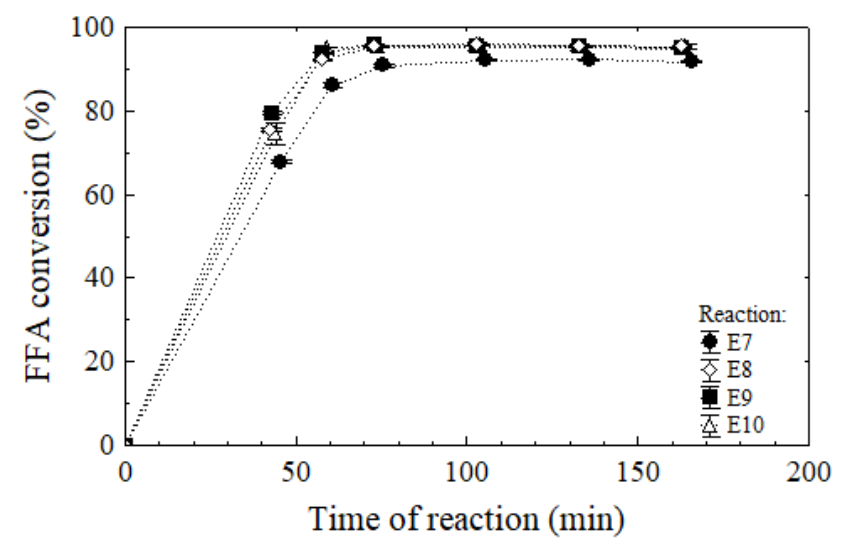

Figure 5. Comparison of results obtained for the methyl esterification of lauric acid using different molar ratios at $\mathrm{T}=180{ }^{\circ} \mathrm{C}$ and Cat. $\approx 40 \mathrm{~g} \mathrm{~L}^{-1}$. Symbols represent experimental data obtained for reactions using $\mathrm{MR}=$ 3.05:1 (squares, E7), MR $\approx 5.97: 1$ (diamonds, E8), MR $\approx 11.94: 1$ (squares, $\mathrm{E} 9$ ) and $\mathrm{MR} \approx 49.79: 1$ (triangles, E10). Dotted lines are a guide for the eye. 
heater) attached to a controller. The heating of the reaction medium is a function of the controller and, since esterification reactions are affected well by the temperature, this factor plays a major role in the reaction conversions (as confirmed by the comparison between reactions E3 and E8, performed using the same reaction conditions). Therefore, heating ramps were obtained for each reaction and are shown in Fig. A.3 (see Appendix).

\section{Transesterification of soybean oil}

The composition of the refined soybean oil used for transesterification reactions, as determined by $\mathrm{GC}$, was $98.8 \%$ of TAG, $1.1 \%$ of DAG and $0.1 \%$ of MAG. Previous GC analyses performed for samples with known composition provided relative errors of 3.72 $\%$ and $4.72 \%$ for the contents of FAME and TAG, respectively, while absolute errors for the contents of MAG and DAG were $2.31 \%$ and $6.19 \%$, respectively. The FFA content of the soybean oil was neglected, since titration analysis provided a value of $(0.13 \pm 0.02)$ $\%$.

Methyl transesterification reactions catalyzed by zinc monoglycerolate were performed using the conditions presented in Table 4, which corresponded to 5 reactions with 6 samples each, resulting in a total of 30 experimental data. The temperature range tested in this work, from $140^{\circ} \mathrm{C}$ to $180^{\circ} \mathrm{C}$, is higher than the maximum temperatures tested in the works of Lisboa et al. (2013) $\left(120^{\circ} \mathrm{C}\right)$ and Reinoso et al. (2014) (140 $\left.{ }^{\circ} \mathrm{C}\right)$. This temperature range was chosen in an attempt to achieve better results in less time of reaction and was possible due to the fact that this solid is stable until nearly $360^{\circ} \mathrm{C}$ (as determined by TGA analysis).

The molar ratios of these reactions were determined by comparing the number of moles of methanol to the total number of moles of acylglycerols (MAG, DAG and TAG), while the catalyst amount is presented as the mass of solids for each $100 \mathrm{~g}$ of soybean oil. Thus, the molar masses of the acylglycerols were achieved based on the FFA profile of soybean oil obtained by gas chromatography. This procedure was employed by Voll et al. (2013) and considers that the acylglycerols are composed of one, two or three alkyl groups derived from the FFAs that are bonded to the glycerol backbone. Therefore, because the

Table 4. Experimental conditions for the transesterification of soybean oil with methanol using zinc monoglycerolate as catalyst.

\begin{tabular}{cccc}
\hline Reaction & T $\left({ }^{\circ} \mathbf{C}\right)$ & MR & Cat. $(\%)$ \\
\hline T1 & 140 & $50.18: 1$ & 2.02 \\
T2 & 160 & $49.88: 1$ & 2.00 \\
T3 & 180 & $50.64: 1$ & 2.02 \\
T4 & 140 & $49.22: 1$ & 0 \\
T5 & 180 & $48.55: 1$ & 0 \\
\hline
\end{tabular}

MR $=$ Molar Ratio alcohol:acylglycerols; Cat. $=$ Catalyst load expressed as $g$ of catalyst per $100 \mathrm{~g}$ of soybean oil.
FFA profile was obtained $(\mathrm{C} 16: 0=(10.14 \pm 0.87) \%$, $\mathrm{C} 18: 0=(0.0414 \pm 0.62) \%, \mathrm{C} 18: 1=(25.96 \pm 2.26) \%$, $\mathrm{C} 18: 2=(51.77 \pm 3.30) \%$ and $\mathrm{C} 18: 3=(8.00 \pm 2.26) \%)$, it was also possible to achieve the mean molar mass of the alkyl group $\left(235.32 \mathrm{~g} \cdot \mathrm{mol}^{-1}\right)$, so as the mean molar masses of MAG (354.42 $\left.\mathrm{g} \mathrm{mol}^{-1}\right)$, DAG (616.74 $\mathrm{g} \mathrm{mol}^{-}$ $\left.{ }^{1}\right)$ and TAG (879.06 $\left.\mathrm{g} \mathrm{mol}^{-1}\right)$.

The compositions obtained for reactions $\mathrm{T} 1$ to T5 were plotted in Figs. A.4.A-E (Appendix). The comparison of the contents of both FAME and TAG obtained for reactions performed either in the absence or in the presence of ZnMGly are presented in Figs. 6.A-D. From Fig. 6.C, it is possible to note a considerable amount of FAME after $6 \mathrm{~h}$ of reaction, performed in the absence of catalyst, at $180{ }^{\circ} \mathrm{C}$ and molar ratio of nearly 50:1. Therefore, it is clear that zinc monoglycerolate presents catalytic activity for this kind of reactions, as confirmed by both the higher initial reaction rate and also by the final content of FAME (91.9\%), which is higher, and of TAG (0.89 $\%$ ), which is lower, as compared to the contents obtained for the reaction performed without catalyst ( $68.5 \%$ and $10.5 \%$, respectively). However, it is also clear that the thermal effects could not be neglected if the kinetics modeling of these data were performed.

Figs. 7.A-B present the effect of temperature on the zinc monoglycerolate-catalyzed reactions and the results indicated that this parameter has a positive effect in the reaction rates of both FAME formation (Fig. 7.A) and TAG consumption (Fig. 7.B). Furthermore, after $6 \mathrm{~h}$ of reaction, at $140{ }^{\circ} \mathrm{C}$ the TAG conversion was $78.3 \%$ and the FAME yield was $53.2 \%$, while these values were, respectively, $88.1 \%$ and $71.4 \%$ at $160{ }^{\circ} \mathrm{C}$ and $99.1 \%$ and $92.7 \%$ at $180{ }^{\circ} \mathrm{C}$.

\section{Processing of high-acidity oils}

The processing of high-acidity oils was carried out in duplicate through sequential reactions of esterification and transesterification, using a mixture containing soybean oil and lauric acid, whose content was nearly $40 \%$, on a mass basis. This FFA was chosen due to its absence in the fatty acid profile of soybean oil, which could help the monitoring of each reaction. Table 5 presents the reaction conditions, in which molar ratios represent the relationship between the amounts of methanol and fatty materials that could produce FAME (both free fatty acids and acylglycerols). The initial contents of each compound in the second step (transesterification reaction) were considered to be the same as the contents of samples obtained after 1 $\mathrm{h}$ of esterification reaction. The reaction conditions for the processing of high-acidity oils were slightly different from those employed for both esterification and transesterification reactions presented previously, especially concerning the molar ratios and catalyst loads. 

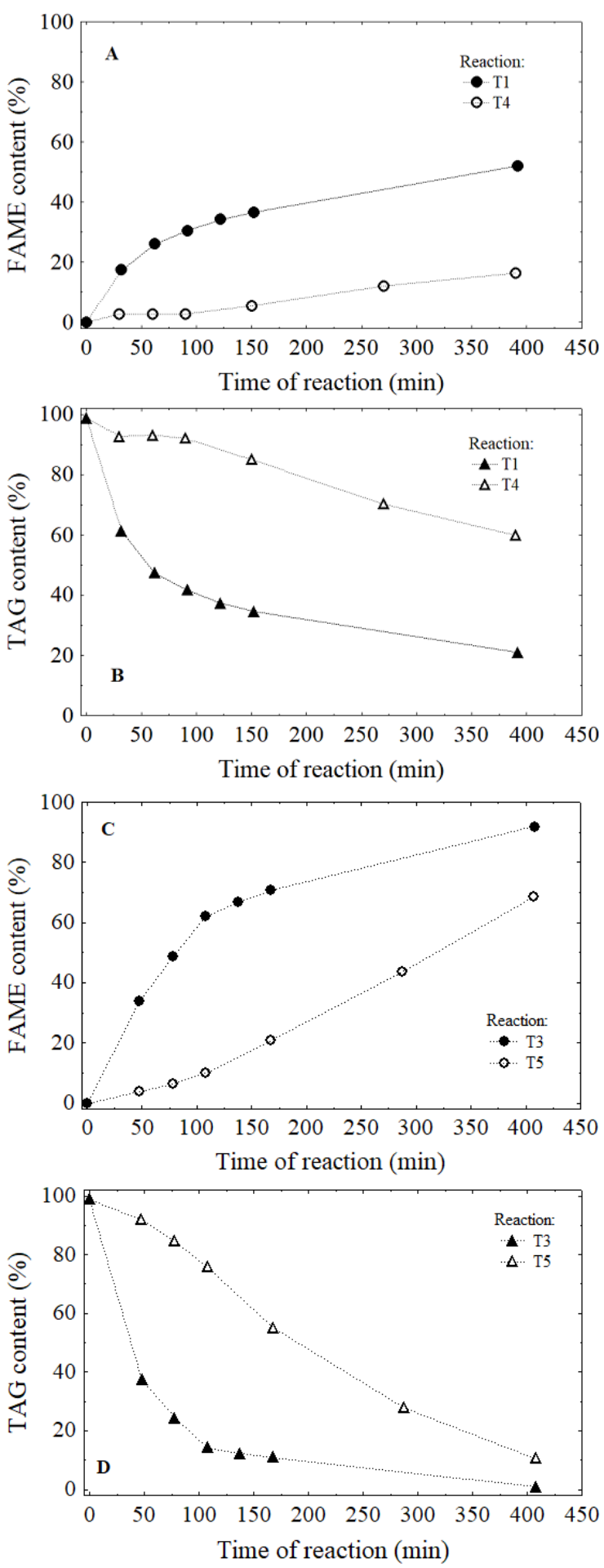

Figure 6. Comparison of (A, C) FAME and (B, D) TAG contents obtained for the methyl transesterification of soybean oil using zinc monoglycerolate as catalyst. The symbols represent experimental data obtained for reactions without catalyst (empty symbols) and using zinc monoglycerolate (full symbols). Reaction conditions were: $\mathrm{T} 1$ (Cat. $=2.02 \%, \mathrm{MR}=50.18: 1$ and $\left.\mathrm{T}=140{ }^{\circ} \mathrm{C}\right), \mathrm{T} 3($ Cat. $=2.02 \%, \mathrm{MR}=50.64: 1$ and $\left.\mathrm{T}=180{ }^{\circ} \mathrm{C}\right), \mathrm{T} 4($ Cat. $=0 \%, \mathrm{MR}=49.22: 1$ and $\left.\mathrm{T}=140{ }^{\circ} \mathrm{C}\right)$ and $\mathrm{T} 5($ Cat. $=0 \%, \mathrm{MR}=48.55: 1$ and $\mathrm{T}=180^{\circ} \mathrm{C}$ ). Dotted lines are a guide for the eye.
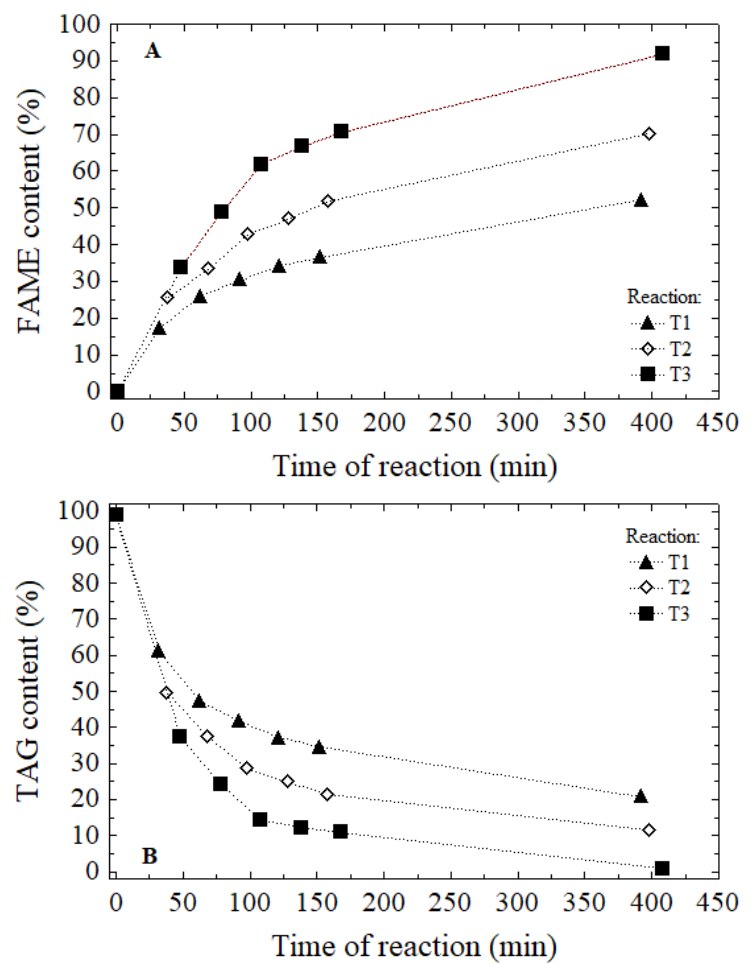

Figure 7. Temperature effect in the contents of both (A) FAME and (B) TAG obtained for the methyl transesterification of soybean oil using zinc monoglycerolate (Cat. $\approx 2 \%$ and $\mathrm{MR} \approx 50: 1$ ). The symbols represent experimental data obtained for reactions $\mathrm{T} 1$ (triangles, $\mathrm{T}=140{ }^{\circ} \mathrm{C}$ ), $\mathrm{T} 2$ (diamonds, $\mathrm{T}$ $=160{ }^{\circ} \mathrm{C}$ ), and $\mathrm{T} 3$ (squares, $\mathrm{T}=180^{\circ} \mathrm{C}$ ). Dotted lines are a guide for the eye.

As for the catalyst loads, the conventional manner is to represent the mass of catalyst used for each 100 $\mathrm{g}$ of the fatty material (Lisboa et al., 2014; Zatta et al., 2014). However, for the processing of high-acidity oil, the most proper form to present this variable is probably in terms of the concentration of catalyst $\left(\mathrm{g} \mathrm{L}^{-1}\right)$. In order to assess the volume of the reaction medium, the same strategy used by Kanda et al. (2017) was employed in this work, using experimental data available in the literature (Huber et al., 2009; Ndiaye et al., 2006; Nogueira et al., 2010; Noureddini and Zhu, 1997) to fit the parameters for equations that related densities of pure components to the temperature. In the case of methanol, the equation and respective parameters were taken from the DIPPR database. The density values used in this work are presented in Table A.1 (Appendix).

This particular study ended up providing 15 samples and the results of analyses performed by GC and titration are shown in Figs. 8.A-B. The esterification of high-acidity oils using montmorillonite K10 under the conditions employed in this work allowed the reduction of FFA contents from $40.7 \%$ to $2.7 \%$ and from 40.8 $\%$ to $3.4 \%$. Hence, FFA conversions of $84.3 \%$ and 
Table 5. Experimental conditions employed for the simulation of the processing of acid oils using the methanol route.

\begin{tabular}{ccccccc}
\hline Reaction & $\mathbf{t}(\mathbf{h})$ & $\mathbf{T}\left({ }^{\circ} \mathbf{C}\right)$ & MR & Cat. $\left(\mathbf{g ~ L ~}^{-1}\right)$ & FFA $_{\mathbf{0}}(\mathbf{\%})$ & FAME $_{\mathbf{0}}(\mathbf{\%})$ \\
\hline E11 & 1 & 160 & $5.93: 1$ & 35.8 & 40.7 & 0 \\
T6 & 2 & 180 & $43.30: 1$ & 3.87 & 2.7 & 42.9 \\
E12 & 1 & 160 & $5.95: 1$ & 35.9 & 40.8 & 0 \\
T7 & 2 & 180 & $39.31: 1$ & 3.83 & 3.4 & 38.1 \\
\hline
\end{tabular}

$\mathrm{t}=$ Time of reaction; $\mathrm{T}=$ Temperature; $\mathrm{MR}=$ Molar Ratio alcohol:fatty materials (FFA + acylglycerols); Cat. $=$ Catalyst load expressed as $\mathrm{g}$ of catalyst per liter of reaction media; FFA0 $=$ Initial FFA content; FAME0 = Initial FAME content.
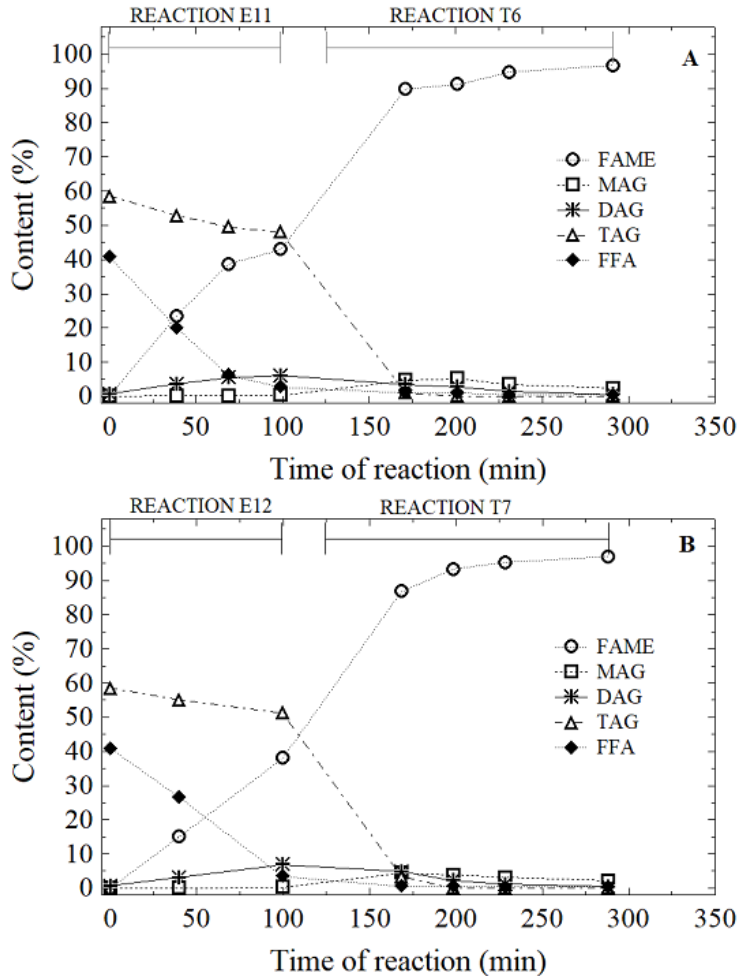

Figure 8. Monitoring of composition of the samples obtained from the processing of acid oil using the methanol route, performed in duplicate (A) and (B). The symbols represent experimental data obtained for esterification reactions using montmorillonite $\mathrm{K} 10$ (reactions E11 and E12, Cat. $\approx 36 \mathrm{~g} \mathrm{~L}^{-1}, \mathrm{FFA}_{0} \approx 40 \%$, $\mathrm{MR} \approx 6: 1$ and $\mathrm{T}=160{ }^{\circ} \mathrm{C}$ ) and for transesterification reactions using zinc monoglycerolate (reactions $\mathrm{T} 6$ and $\mathrm{T} 7$, Cat. $\approx 4 \mathrm{~g} \mathrm{~L}^{-1}, \mathrm{MR} \approx 40: 1$ and $\left.\mathrm{T}=180{ }^{\circ} \mathrm{C}\right)$. Lines are a guide for the eye.

$78.1 \%$ were obtained, while the esterification of lauric acid without the presence of soybean oil (reaction E2) provided a conversion of $94.5 \%$ after $1 \mathrm{~h}$ of reaction. This difference might be due to the fact that the catalyst concentration in the latter reaction was of $42.4 \mathrm{~g} \mathrm{~L}^{-1}$, while for the processing of acid oil this value was around $36 \mathrm{~g} \mathrm{~L}^{-1}$. Moreover, TAG conversions obtained after the esterification reaction using montmorillonite $\mathrm{K} 10$, performed in duplicate, were $7.5 \%$ and $4.1 \%$, while after $1 \mathrm{~h}$ in the transesterification reaction $\mathrm{T} 2$, using zinc monoglycerolate, performed at the same temperature $\left(160^{\circ} \mathrm{C}\right)$, this value was $70.3 \%$. This result indicates that montmorillonite $\mathrm{K} 10$ does not present a good catalytic activity towards the transesterification of acylglycerols.

On the other hand, unlike the transesterification reactions performed using pure soybean oil, the second step of the processing of high-acidity fatty materials occurred almost to completion, since TAG conversions were virtually $100 \%$ (as no TAG was detected by the end of the $2 \mathrm{~h}$ transesterification reaction) and small contents of DAG (2.4\% and $2.2 \%)$ and MAG $(0.53$ $\%$ and $0.42 \%$ ) were detected in both the reactions performed. As a matter of fact, low contents of the acylglycerols were observed even for the first samples obtained in each reaction (right after the desired temperature for the reactions was reached). The presence of small amounts of FFA may be responsible for the enhancement of the transesterification reaction when zinc monoglycerolate is used as catalyst (Reinoso et al., 2014).

A comparison between the performances of various solid catalysts in esterification and transesterification reactions performed under different conditions, obtained in this work and in previous studies, is shown in Table 6. Results from this work are related to the processing of high-acidity fatty materials, in which sequential esterification and transesterification reactions were performed. Thus, conversions of both TAG and FFA, as well as FAME yields presented for the reactions using zinc monoglycerolate were assessed considering the amounts of the chemical species in the beginning of the processing. From this comparison, it is easy to infer that solid catalysts, in general, require either higher reaction times or higher temperatures, as compared to homogeneous catalysts, so as high FAME yields are obtained.

It worth mentioning that the material obtained after the esterification step could be processed by the traditional means of alkaline transesterification. However, zinc monoglycerolate can be easily recovered and reused in the reaction (Lisboa et al., 2013; Reinoso et al., 2014), which makes its use interesting even though these reactions require more time to achieve high FAME yields. The approach followed in this work for the processing of high-FFA content raw materials can successfully result in high FAME yields (95.3\% and $95.5 \%$ ) after reasonable times of reaction. 
Table 6. Performance comparison of various solid catalysts used in previous studies and in this work for the production of biodiesel.

\begin{tabular}{|c|c|c|c|c|c|c|c|c|c|}
\hline Reference & Catalyst & $\begin{array}{c}\text { FFA }_{0} \\
(\%)\end{array}$ & MR & $\begin{array}{c}\text { t } \\
(\mathbf{h})\end{array}$ & $\mathbf{T}\left({ }^{\circ} \mathbf{C}\right)$ & Cat. (\%) & $\begin{array}{c}X_{\text {TAG }} \\
(\%)\end{array}$ & $\begin{array}{l}\mathbf{X}_{\text {FFA }} \\
(\%)\end{array}$ & $\begin{array}{c}\mathbf{y}_{\text {FAME }} \\
(\%)\end{array}$ \\
\hline $\begin{array}{c}\text { Kwong \& Yung } \\
\text { (2016) }\end{array}$ & $\begin{array}{c}\text { Zinc oxide / } \\
\text { zinc glycerolate }\end{array}$ & $\begin{array}{l}0 \\
6\end{array}$ & $30: 1$ & $\begin{array}{c}0.5 \\
2\end{array}$ & 140 & 8 & $\begin{array}{c}0.8 \\
98.5\end{array}$ & - & - \\
\hline $\begin{array}{l}\text { Reinoso et al. } \\
\text { (2014) }\end{array}$ & Zinc glycerolate & $\begin{array}{c}10 \\
100\end{array}$ & $30: 1$ & $\begin{array}{l}2 \\
1\end{array}$ & 140 & 3 & $\begin{array}{c}99.5 \\
-\end{array}$ & - & $\begin{array}{c}93.8 \\
-\end{array}$ \\
\hline $\begin{array}{l}\text { Pan et al. } \\
\text { (2018) }\end{array}$ & $\begin{array}{l}\text { 1,3-disulfonic acid } \\
\text { imidazolium chloride } \\
\text { 1,3-disulfonic acid } \\
\text { imidazolium } \\
\text { tetrachloroferrate }\end{array}$ & 1.78 & $15: 1$ & 8 & 120 & 5 & - & - & 86 \\
\hline Wang et al. (2017) & $\begin{array}{l}\text { Bifunctional magnetic } \\
\text { acid }\end{array}$ & $\begin{array}{l}60 \\
8.6\end{array}$ & $12: 1$ & $\begin{array}{l}8 \\
3\end{array}$ & $\begin{array}{c}140 \\
90\end{array}$ & $\begin{array}{l}7 \\
9\end{array}$ & $\begin{array}{l}- \\
-\end{array}$ & $\overline{9}-$ & $\begin{array}{c}93.07 \\
-\end{array}$ \\
\hline Dawodu et al. (2014) & & 15 & $30: 1$ & 5 & $\begin{array}{l}150 \\
180\end{array}$ & $\begin{array}{c}6 \\
7.6\end{array}$ & $\begin{array}{l}- \\
-\end{array}$ & $\begin{array}{c}87.2 \\
-\end{array}$ & $\begin{array}{l}75 \\
99\end{array}$ \\
\hline Fadhil et al. (2016) & Sulfonated carbon & 10 & $15: 1$ & 6 & $\begin{array}{l}60 \\
68\end{array}$ & 6 & $\begin{array}{l}- \\
-\end{array}$ & $\begin{array}{r}\sim 85 \\
94.4\end{array}$ & $\begin{array}{l}- \\
-\end{array}$ \\
\hline Konwar et al. (2013) & & $\begin{array}{c}8.17 \\
14.4 \\
43.73\end{array}$ & $\begin{array}{c}43: 1 \\
10.8: 1 \\
10.8: 1\end{array}$ & 6 & $\begin{array}{c}100 \\
80\end{array}$ & 5 & $\begin{array}{l}- \\
- \\
-\end{array}$ & $\begin{array}{l}\sim 99 \\
\sim 97 \\
\sim 99\end{array}$ & $\begin{array}{l}- \\
-\end{array}$ \\
\hline This work & Montmorillonite $\mathrm{K} 10$ & $\begin{array}{c}40.7 \\
40.8 \\
2.7 \\
3.4\end{array}$ & $\begin{array}{c}5.9: 1 \\
6.0: 1 \\
53.7: 1 \\
49.7: 1\end{array}$ & $\begin{array}{l}1 \\
1 \\
2 \\
2\end{array}$ & $\begin{array}{l}160 \\
160 \\
180 \\
180\end{array}$ & $\begin{array}{c}6.63 \\
6.65 \\
2.2 \\
2.2\end{array}$ & $\begin{array}{l}7.53 \\
4.07 \\
100^{\mathrm{a}} \\
100^{\mathrm{a}}\end{array}$ & $\begin{array}{c}84.3 \\
78.1 \\
99.2^{\mathrm{a}} \\
98.6^{\mathrm{a}}\end{array}$ & $\begin{array}{r}43.4 \\
39.8 \\
95.3^{\mathrm{a}} \\
95.5^{\mathrm{a}}\end{array}$ \\
\hline
\end{tabular}

FFA0 = Initial FFA content; MR = Molar Ratio alcohol:fatty materials (FFA + acylglycerols); $\mathrm{t}=$ Time of reaction; $\mathrm{T}=$ Temperature; Cat. $=$ Catalyst load expressed as $\mathrm{g}$ of catalyst per $100 \mathrm{~g}$ of fatty material (FFA + acylglycerols); X TAG = TAG conversion; X FFA = FFA conversion; y FAME = FAME yield. a Results were assessed considering the amounts before esterification reactions using montmorillonite $\mathrm{K} 10$.

\section{Zinc monoglycerolate characterization after the reactions}

After the catalyst recovery and purification following the procedures described earlier, the solids were analyzed by XRD to determine whether they maintained their integrity. Results obtained for zinc monoglycerolate prior to the reactions and those recovered after the methyl transesterification of soybean oil are presented in Fig.A.5 (Appendix), while the results for the analysis of solids employed in the processing of acid oils are presented in Fig. 9.A. Slightly different diffraction angles were observed, mainly caused by inherent errors of the equipment, meaning that no significant changes were detected in the catalysts recovered after the methyl transesterification of soybean oil, especially since the zinc oxide diffraction pattern was not identified in the samples. Moreover, zinc monoglycerolate recovered after the two-step processing of the high-acidity oil also remained intact, as diffraction patterns of zinc laurate (expected if zinc monoglycerolate reacted with lauric acid) were not identified. The recovered solids were likewise subjected to FTIR and TGA analyses.

The FTIR spectra of zinc monoglycerolate recovered after reactions $\mathrm{T} 6$ and $\mathrm{T} 7$ are presented in Fig. 9.B and show a good agreement with the spectrum of the zinc monoglycerolate before the reactions (batch \#1), indicating that the catalyst suffered no significant changes. Despite that, the recovered solids presented noise between 3500 and $4000 \mathrm{~cm}^{-1}$ and there is evidence for the presence of water in the zinc monoglycerolate before the reactions via the broad band between 3300 and $3400 \mathrm{~cm}^{-1}$, attributed to O-H stretching. Narrow bands were identified between 2800 and $3000 \mathrm{~cm}^{-1}$ and are related to the vibrational modes of $\mathrm{C}-\mathrm{H}$ e $\mathrm{H}-\mathrm{C}-\mathrm{H}$ groups. Vibrations related to the stretching of C-O bonds are identified near 1900 $\mathrm{cm}^{-1}$ and $1100 \mathrm{~cm}^{-1}$ (the first of which is related to the hydrogen bond $\mathrm{C}-\mathrm{O} \cdots \mathrm{H}-\mathrm{O})$. Finally, a narrow band is observed close to $875 \mathrm{~cm}^{-1}$ and is related to the $\mathrm{Zn}$ $\mathrm{O}-\mathrm{C}$ bending modes, while metal-oxygen ( $\mathrm{Zn}-\mathrm{O})$ stretching bands are observed at $650 \mathrm{~cm}^{-1}$ and 400 $\mathrm{cm}^{-1}$, confirming the coordination of the metal to the monoglycerolate anion. These results are consistent with those presented by Lisboa et al. (2013) and Reinoso et al. (2014).

Finally, Figs. 9.C-D show the thermogravimetric analyses for the solids recovered after the processing of acid oil performed in duplicate, in which the same thermal events are identified and that also present a good agreement with the TGA of zinc monoglycerolate prior to the reactions (Fig. A.2 - Appendix). Very close temperatures of onset and of the $1^{\text {st }}$ derivative peak were also observed and, by the end of the analysis, the solids recovered after reactions $\mathrm{T} 6$ and $\mathrm{T} 7$ presented final zinc oxide contents of $49.7 \%$ and $49.1 \%$, while the solids prior to the reactions presented $50.3 \%$ of this content (as mentioned before). All the calculations were performed on a dry basis. 

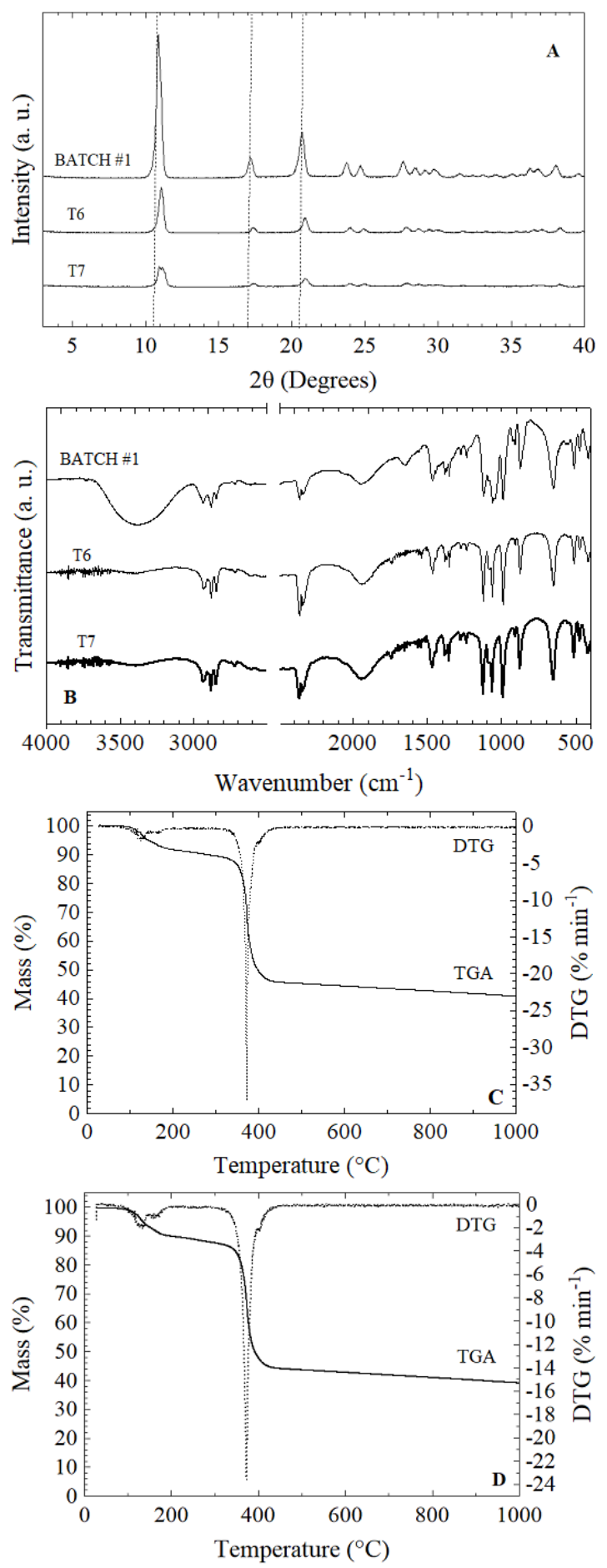

Figure 9. Analyses of zinc monoglycerolate recovered after the processing of high-acidity fatty materials, reactions $\mathrm{T} 6$ and $\mathrm{T} 7$ (Cat. $\approx 4 \mathrm{~g} \cdot \mathrm{L}^{-1}, \mathrm{MR} \approx 40: 1$ and $\mathrm{T}=180{ }^{\circ} \mathrm{C}$ ). (A) Comparison of XRD analysis of zinc monoglycerolate before and after reactions (dashed lines are a guide for the eye); (B) Comparison of FTIR spectra of zinc monoglycerolate before and after reactions; thermal analysis curves (TGA/DTG) of zinc monoglycerolate after reactions (C) T6 and (D) T7 (continuous lines indicate thermogravimetric curves and dotted lines refer to the thermogravimetric derivatives).
All the analyses presented indicated that the zinc monoglycerolate retained its integrity and thus can be considered as a stable material under the conditions tested, proving the possibility of using this solid for the processing of acid oil. Even though it was possible that zinc carboxylates were formed during the reaction, according to Reinoso et al. (2014), the formation of glycerol during the course of the reaction contributes to the metal carboxylate to shift it back to the metal monoglycerolate. Furthermore, zinc oxide might be present if the heating mantle temperature reached higher values (according to the thermal analysis, the zinc monoglycerolate oxidation begins at approximately $360^{\circ} \mathrm{C}$ ).

\section{CONCLUSION}

The two-step process using solid catalysts, montmorillonite $\mathrm{K} 10$ to reduce the FFA content of acid oils, followed by the use of zinc monoglycelorate to perform the transesterification reaction, had its technical feasibility demonstrated for the prompt usage of oils with high-acidity aiming at biodiesel production. The main results achieved were a reduction of $(92.6 \pm 1.2) \%$ in the FFA content after the first step and a final FAME content of $(96.6 \pm 0.2) \%$. Considering the conditions employed in this work, the industrial use of both solid catalysts seems to be promising, especially considering the possibility of their recovery and further reuse in the process (the latter was not performed in this work). Furthermore, the results obtained may encourage the production of biodiesel from otherwise unusual raw materials, especially regarding higher acidity fatty materials, whose processing result in both environmental and economic gains.

\section{ACKNOWLEDGEMENTS}

The authors are thankful to the Brazilian funding agencies (CNPq - Proc. Num. 303846/2014-3 and 40117/2016-9, CAPES - Finance Code 001 and Fundação Araucária) for the financial aid of this work. We are also grateful for the analytical support provided by Laboratório de Óptica de Raios X e Instrumentação (LORXI - UFPR), Laboratório de Espectroscopia de Absorção no Infravermelho (Chemistry Department - UFPR), Centro de Microscopia Eletrônica (CMEUFPR) and Central Analítica (Chemical Engineering Department - UFPR).

\section{REFERENCES}

Almeida, V. F. de, García-Moreno, P. J., Guadix, A., Guadix, E. M. Biodiesel production from mixtures of waste fish oil, palm oil and waste frying oil: 
Optimization of fuel properties. Fuel Processing Technology, 133, 152-160 (2015). https://doi. org/10.1016/j.fuproc.2015.01.041

Boocock, D. G. B., Konar, S. K., Leung, A., Ly, L. D. Fuels and chemicals from sewage sludge. 1. The solvent extraction and composition of a lipid from a raw sewage sludge. Fuel, 71, 1283-1289 (1992). https://doi.org/10.1016/0016-2361(92)90055-S

Canakci, M., Gerpen, J. van. Biodiesel Production from Oils and Fats with High Free Fatty Acids. Transactions of the ASAE, 44, 1429-1436 (2001). https://doi.org/10.13031/2013.7010

Cordeiro, C. S., Silva, F. R. da, Marangoni, R., Wypych, F., Ramos, L. P. LDHs instability in esterification reactions and their conversion to catalytically active layered carboxylates. Catalysis Letters, 142, 763-770 (2012). https://doi.org/10.1007/s10562012-0819-Z

Dantas, J., Leal, E., Mapossa, A. B., Cornejo, D. R., Costa, A. C. F. M. Magnetic nanocatalysts of $\mathrm{Ni} 0.5 \mathrm{Zn} 0.5 \mathrm{Fe} 2 \mathrm{O} 4 d$ doped with $\mathrm{Cu}$ and performance evaluation in transesterification reaction for biodiesel production. Fuel, 191, 463-471 (2017). https://doi.org/10.1016/j.fuel.2016.11.107

Dawodu, F. A., Ayodele, O., Xin, J., Zhang, S., Yan, D. Effective conversion of non-edible oil with high free fatty acid into biodiesel by sulphonated carbon catalyst. Applied Energy, 114, 819-826 (2014). https://doi.org/10.1016/j.apenergy.2013.10.004

Dias, J. M., Alvim-Ferraz, M. C. M., Almeida, M. F., Méndez Díaz, J. D., Polo, M. S., Utrilla, J. R. Selection of heterogeneous catalysts for biodiesel production from animal fat. Fuel, 94, 418-425 (2012). https://doi.org/10.1016/j.fuel.2011.10.069

Encinar, J. M., Sánchez, N., Martínez, G., García, L. Study of biodiesel production from animal fats with high free fatty acid content. Bioresource Technology, 102, 10907-10914 (2011). https://doi. org/10.1016/j.biortech.2011.09.068

Fadhil, A. B., Aziz, A. M., Al-Tamer, M. H. Biodiesel production from Silybum marianum L. seed oil with high FFA content using sulfonated carbon catalyst for esterification and base catalyst for transesterification. Energy Conversion and Management, 108, 255-265 (2016). https://doi. org/10.1016/j.enconman.2015.11.013

Haas, M. J. Improving the economics of biodiesel production through the use of low value lipids as feedstocks: Vegetable oil soapstock. Fuel Processing Technology, 86, 1087-1096 (2005). https://doi.org/10.1016/j.fuproc.2004.11.004

Hamerski, F., Corazza, M. L. LDH-catalyzed esterification of lauric acid with glycerol in solvent-free system. Applied Catalysis A: General, 475, 242-248 (2014). https://doi.org/10.1016/j. apcata.2014.01.040
Huber, M. L., Lemmon, E. W., Kazakov, A., Ott, L. S., Bruno, T. J. Model for the thermodynamic properties of a biodiesel fuel. Energy and Fuels, 23, 3790-3797 (2009). https://doi.org/10.1021/ ef $900159 \mathrm{~g}$

Istadi, I., Anggoro, D. D., Buchori, L., Rahmawati, D. A., Intaningrum, D. Active Acid Catalyst of Sulphated Zinc Oxide for Transesterification of Soybean Oil with Methanol to Biodiesel. Procedia Environmental Sciences, 23, 385-393 (2015). https://doi.org/10.1016/j.proenv.2015.01.055

Jindapon, W., Jaiyen, S., Ngamcharussrivichai, C. Seashell-derived mixed compounds of $\mathrm{Ca}$, $\mathrm{Zn}$ and $\mathrm{Al}$ as active and stable catalysts for the transesterification of palm oil with methanol to biodiesel. Energy Conversion and Management, 122, 535-543 (2016). https://doi.org/10.1016/j. enconman.2016.06.012

Kanda, L. R. S., Corazza, M. L., Zatta, L., Wypych, F. Kinetics evaluation of the ethyl esterification of long chain fatty acids using commercial montmorillonite K10 as catalyst. Fuel, 193, 265-274 (2017). https:// doi.org/10.1016/j.fuel.2016.12.055

Koizumi, T. Biofuels and food security. Renewable and Sustainable Energy Reviews, 52, 829-841 (2015). https://doi.org/10.1016/j.rser.2015.06.041

Konwar, L. J., Das, R., Thakur, A. J., Salminen, E., Mäki-Arvela, P., Kumar, N., Mikkola, J. P., Deka, D. Biodiesel production from acid oils using sulfonated carbon catalyst derived from oil-cake waste. Journal of Molecular Catalysis A: Chemical, 388-389, 167-176 (2014). https://doi.org/10.1016/j. molcata.2013.09.031

Kouzu, M., Yamanaka, S., Hidaka, J., Tsunomori, M. Heterogeneous catalysis of calcium oxide used for transesterification of soybean oil with refluxing methanol. Applied Catalysis A: General, 355, 94-99 (2009). https://doi.org/10.1016/j. apcata.2008.12.003

Kwon, E. E., Kim, S., Jeon, Y. J., Yi, H. Biodiesel production from sewage sludge: New paradigm for mining energy from municipal hazardous material. Environmental Science and Technology, 46, 1022210228 (2012). https://doi.org/10.1021/es3019435

Kwong, T. L., Yung, K. F. One-step production of biodiesel through simultaneous esterification and transesterification from highly acidic unrefined feedstock over efficient and recyclable $\mathrm{ZnO}$ nanostar catalyst. Renewable Energy, 90, 450-457 (2016). https://doi.org/10.1016/j.renene.2016.01.028

Lau, P. C., Kwong, T. L., Yung, K. F. Effective heterogeneous transition metal glycerolates catalysts for one-step biodiesel production from low grade non-refined Jatropha oil and crude aqueous bioethanol. Scientific Reports, 6, 1-10 (2016). https://doi.org/10.1038/srep23822 
León-Reina, L., Cabeza, A., Rius, J., Maireles-Torres, P.,Alba-Rubio,A.C., López Granados, M. Structural and surface study of calcium glyceroxide, an active phase for biodiesel production under heterogeneous catalysis. Journal of Catalysis, 300, 30-36 (2013). https://doi.org/10.1016/j.jcat.2012.12.016

Lisboa, F. D. S., Silva, F. R. da, Cordeiro, C. S., Ramos, L. P., Wypych, F. Metal glycerolates as catalysts in the transesterification of refined soybean oil with methanol under reflux conditions. Journal of the Brazilian Chemical Society, 25, 1592-1600 (2014). https://doi.org/10.5935/0103-5053.20140144

Lisboa, F. D. S., Silva, F. R. da, Ramos, L. P., Wypych, F. Zinc monoglycerolate as highly active and reusable catalyst in the methyl transesterification of refined soybean oil. Catalysis Letters, 143, 1235-1239 (2013). https://doi.org/10.1007/s10562-013-1050-2

López Granados, M., Alba-Rubio, A. C., Vila, F., Martín Alonso, D., Mariscal, R. Surface chemical promotion of $\mathrm{Ca}$ oxide catalysts in biodiesel production reaction by the addition of monoglycerides, diglycerides and glycerol. Journal of Catalysis, 276, 229-236 (2010). https://doi. org/10.1016/j.jcat.2010.09.016

Lukić, I., Kesić, Ž., Zdujić, M., Skala, D. Calcium diglyceroxide synthesized by mechanochemical treatment, its characterization and application as catalyst for fatty acid methyl esters production. Fuel. 165, 159-165 (2016). https://doi.org/10.1016/j. fuel.2015.10.063

Marchetti, J. M., Pedernera, M. N., Schbib, N. S. Production of biodiesel from acid oil using sulfuric acid as catalyst: Kinetics study. International Journal of Low-Carbon Technologies, 6, 38-43 (2011). https://doi.org/10.1093/ijlct/ctq040

Mendow, G., Veizaga, N. S., Sánchez, B. S., Querini, C. A. Biodiesel production by two-stage transesterification with ethanol. Bioresource Technology, 102, 10407-10413 (2011). https://doi. org/10.1016/j.biortech.2011.08.052

Mittelbach, M., Remschmidt, C. Biodiesel: the comprehensive handbook. Paperback, Vienna (2005).

Ndiaye, P. M., Lanza, M., Tavares, F. W., Dariva, C., Oliveira, D., Oliveira, J. V. Phase behavior of olive and soybean oils in compressed propane and N-butane. Brazilian Journal of Chemical Engineering, 23, 405-415 (2006). https://doi. org/10.1590/S0104-66322006000300014

Neji, S. B., Trabelsi, M., Frikha, M. H. Esterification of fatty acids with short-chain alcohols over commercial acid clays in a semi-continuous reactor. Energies, 2, 1107-1117 (2009). https://doi. org/10.3390/en20401107

Neji, S. B., Trabelsi, M., Frikha, M. H. Esterification of fatty acid over Tunisian acid activated clay: Kinetic study. Journal of Oleo Science, 60, 293-299 (2011). https://doi.org/10.5650/jos.60.293

Nogueira, C. A., Feitosa, F. X., Fernandes, F. A. N., Santiago, R. S., Sant'ana, H. B. de. De n s i ti e s and viscosities of binary mixtures of babassu biodiesel + cotton seed or soybean biodiesel at different temperatures. Journal of Chemical and Engineering Data, 55, 5305-5310 (2010). https:// doi.org/10.1021/je1003862

Noureddini, H., Zhu, D. Kinetics of Transesterification of Soybean Oil. Journal of American Oil Chemists' Society, 74, 1457-1463 (1997). https://doi. org/10.1007/s11746-997-0254-2

Olkiewicz, M., Plechkova, N. V., Earle, M. J., Fabregat, A., Stüber, F., Fortuny, A., Font, J., Bengoa, C. Biodiesel production from sewage sludge lipids catalysed by Brønsted acidic ionic liquids. Applied Catalysis B: Environmental, 181, 738-746 (2016). https://doi.org/10.1016/j.apcatb.2015.08.039

Otadi, M., Shahraki, A., Goharrokhi, M., Bandarchian, F. Reduction of free fatty acids of waste oil by acidcatalyzed esterification. Procedia Engineering, 18, 168-174 (2011). https://doi.org/10.1016/j. proeng.2011.11.027

Pan, H., Li, H., Zhang, H., Wang, A., Jin, D., Yang, S. Effective production of biodiesel from nonedible oil using facile synthesis of imidazolium salts-based BrØnsted-Lewis solid acid and cosolvent. Energy Conversion and Management, 166, 534-544 (2018). https://doi.org/10.1016/j. enconman.2018.04.061

Pasupulety, N., Rempel, G. L., Ng, F. T. T. Studies on Mg-Zn mixed oxide catalyst for biodiesel production. Applied Catalysis A: General, 489, 77-85 (2015). https://doi.org/10.1016/j.apcata.2014.10.015

Piloto-Rodríguez, R., Melo, E. A., Goyos-Pérez, L., Verhelst, S. Conversion of by-products from the vegetable oil industry into biodiesel and its use in internal combustion engines: A review. Brazilian Journal of Chemical Engineering, 31, 287-301 (2014). https://doi.org/10.1590/01046632.20140312s00002763

Pires, J., Brasil, B., Araújo, M. E. M. Reduction of free fatty acids in acidic nonedible oils by modified K10 clay. Journal of the American Oil Chemists' Society, 90, 555-561 (2013). https://doi. org/10.1007/s11746-012-2192-x

Pradhan, S., Shen, J., Emami, S., Mohanty, P., Naik, S. N., Dalai, A. K., Reaney, M. J. T. Synthesis of potassium glyceroxide catalyst for sustainable green fuel (biodiesel) production. Journal of Industrial and Engineering Chemistry, 46, 266-272 (2017). https://doi.org/10.1016/j.jiec.2016.10.038

Reinoso, D. M., Damiani, D. E., Tonetto, G. M. Zinc glycerolate as a novel heterogeneous catalyst for the synthesis of fatty acid methyl esters. Applied 
Catalysis B: Environmental, 144, 308-316 (2014). https://doi.org/10.1016/j.apcatb.2013.07.026

Rezende, M. J. C., Pereira, M. S. C., Santos, G. F. N., Aroeira, G. O. P., Albuquerque, T. C., Suarez, P. A. Z., Pinto, A. C. Preparation, characterisation and evaluation of brazilian clay-based catalysts for use in esterification reactions. Journal of the Brazilian Chemical Society, 23, 1209-1215 (2012). https:// doi.org/10.1590/S0103-50532012000700003

Rubio-Caballero, J. M., Santamaría-González, J., Mérida-Robles, J., Moreno-Tost, R., JiménezLópez, A., Maireles-Torres, P. Calcium zincate as precursor of active catalysts for biodiesel production under mild conditions. Applied Catalysis B: Environmental, 91, 339-346 (2009). https://doi.org/10.1016/j.apcatb.2009.05.041

Rukunudin, I. H., White, P. J., Bern, C. J., Bailey, T. B. A modified method for determining free fatty acids from small soybean oil sample sizes. Journal of the American Oil Chemists' Society, 75, 563-568 (1998). https://doi.org/10.1007/s11746-998-0066-z

Santos, P. R. S. dos, Wypych, F., Voll, F. A. P., Hamerski, F., Corazza, M. L. Kinetics of ethylic esterification of lauric acid on acid activated montmorillonite ( STx1-b ) as catalyst. Fuel, 181, 600-609 (2016). https://doi.org/10.1016/j.fuel.2016.05.026

Wang, E., Shen, J., Wang, Y., Tang, S., Emami, S., Reaney, M. J. T. Production of biodiesel with lithium glyceroxide. Fuel, 160, 621-628 (2015). https://doi.org/10.1016/j.fuel.2015.07.101

Wang, Y. T., Fang, Z., Yang, X. X. Biodiesel production from high acid value oils with a highly active and stable bifunctional magnetic acid. Applied Energy, 204, 702-714 (2017). https://doi.org/10.1016/j. apenergy.2017.07.060

Wang, Z. M., Lee, J. S., Park, J. Y., Wu, C. Z., Yuan, Z. H. Novel biodiesel production technology from soybean soapstock. Korean Journal of Chemical Engineering, 24, 1027-1030 (2007). https://doi. org/10.1007/s11814-007-0115-6

Zatta, L., Gardolinski, J. E. F. da C., Wypych, F. Raw halloysite as reusable heterogeneous catalyst for esterification of lauric acid. Applied Clay Science, 51, 165-169 (2011). https://doi.org/10.1016/j. clay.2010.10.020

Zatta, L., Nepel, A., Barison, A., Wypych, F. Montmorilonita modificada como catalisador heterogêneo em reações de esterificação (m) etílica de ácido láurico. Quimica Nova, 35, 1-14 (2012a). https://doi.org/10.1590/S010040422012000900002

Zatta, L., Paiva, E. J., Corazza, M. L., Wypych, F., Ramos, L. P. The Use of Acid-Activated
Montmorillonite as a Solid Catalyst for the Production of Fatty Acid Methyl Esters. Energy and Fuels, 28, 5834-5840 (2014). https://doi. org/10.1021/ef500935q

Zatta, L., Ramos, L. P., Wypych, F. Acid activated montmorillonite as catalysts in methyl esterification reactions of lauric acid. Journal of Oleo science, 61, 497-504 (2012b). https://doi.org/10.5650/ jos.61.497

Zatta, L., Ramos, L. P., Wypych, F. Applied Clay Science Acid-activated montmorillonites as heterogeneous catalysts for the esteri fi cation of lauric acid acid with methanol. Applied Clay Science, 80-81, 236-244 (2013). https://doi. org/10.1016/j.clay.2013.04.009

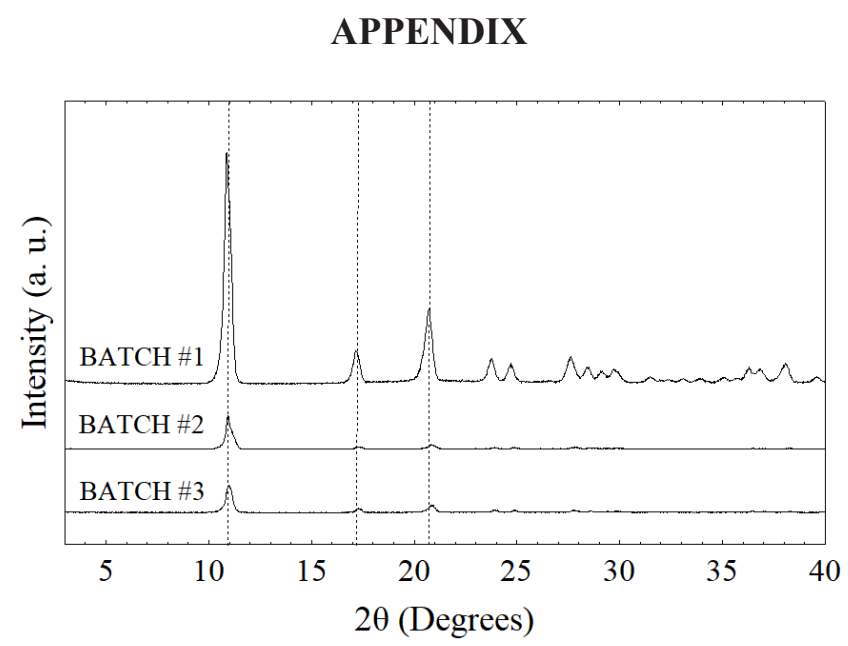

Figure A.1. XRD analysis of zinc monoglycerolate (batches \#1, \#2, and \#3).

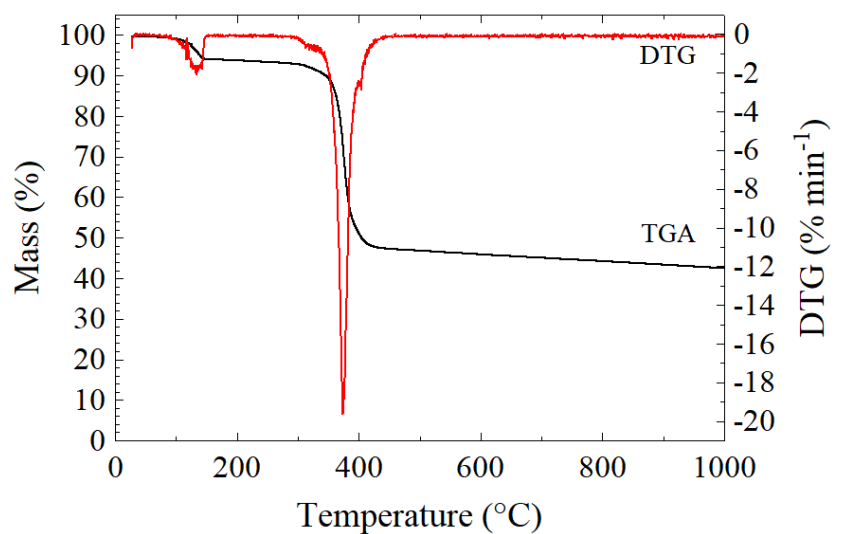

Figure A.2. Thermal analysis curves (TGA/ DTG) of zinc monoglycerolate (batch \#4) used for transesterification of soybean oil. Continuous lines indicate thermogravimetric curves (black) and thermogravimetric derivatives (red). 

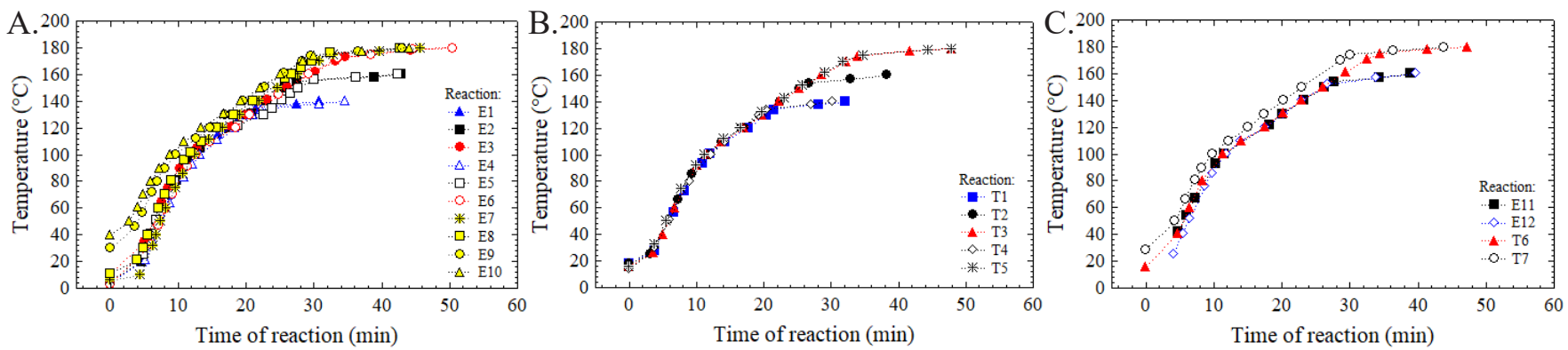

Figure A.3. Heating ramps for (A) esterification reactions using FFA, (B) transesterification reactions using soybean oil and $(\mathrm{C})$ esterification and transesterification reactions using acid oil. The symbols represent experimental data obtained for reactions $E 1$ : Cat. $=12.03 \%, \mathrm{MR}=6.06: 1, \mathrm{~T}=140{ }^{\circ} \mathrm{C} ; E 2$ : Cat. $=12.01 \%, \mathrm{MR}=6.18: 1, \mathrm{~T}=160$ ${ }^{\circ} \mathrm{C} ;$ E3: Cat. $=11.75 \%, \mathrm{MR}=5.97: 1, \mathrm{~T}=180{ }^{\circ} \mathrm{C} ; E 4:$ Cat. $=0 \%, \mathrm{MR}=6.01: 1, \mathrm{~T}=140{ }^{\circ} \mathrm{C} ;$ E5: Cat. $=0 \%$, MR $=$ 6.10:1, $\mathrm{T}=160{ }^{\circ} \mathrm{C} ; E 6:$ Cat. $=0 \%, \mathrm{MR}=6.01: 1, \mathrm{~T}=180{ }^{\circ} \mathrm{C} ; E 7:$ Cat. $=39.7 \mathrm{~g} \mathrm{~L}^{-1}, \mathrm{MR}=3.05: 1, \mathrm{~T}=180{ }^{\circ} \mathrm{C} ; E 8:$ Cat. $=40.7 \mathrm{~g} \mathrm{~L}^{-1}, \mathrm{MR}=5.97: 1, \mathrm{~T}=180^{\circ} \mathrm{C} ; E 9:$ Cat. $=40.3 \mathrm{~g} \mathrm{~L}^{-1}, \mathrm{MR}=11.94: 1, \mathrm{~T}=180^{\circ} \mathrm{C} ; E 10:$ Cat. $=39.8 \mathrm{~g} \mathrm{~L}^{-1}$, $\mathrm{MR}=49.79: 1, \mathrm{~T}=180{ }^{\circ} \mathrm{C} ; \mathrm{Tl}:$ Cat. $=2.02 \%, \mathrm{MR}=50.18: 1, \mathrm{~T}=140{ }^{\circ} \mathrm{C} ; \mathrm{T} 2:$ Cat. $=2.00 \%, \mathrm{MR}=49.88: 1, \mathrm{~T}=$ $160{ }^{\circ} \mathrm{C} ; \mathrm{T3}: \mathrm{Cat} .=2.02 \%, \mathrm{MR}=50.64: 1, \mathrm{~T}=180{ }^{\circ} \mathrm{C} ; \mathrm{T} 4: \mathrm{Cat} .=0 \%, \mathrm{MR}=49.22: 1, \mathrm{~T}=140{ }^{\circ} \mathrm{C} ; \mathrm{T5}:$ Cat. $=0 \%$, $\mathrm{MR}=48.55: 1, \mathrm{~T}=180^{\circ} \mathrm{C} ; E 11$ and $E 12:$ Cat. $\approx 36 \mathrm{~g} \mathrm{~L}^{-1}, \mathrm{FFA}_{0} \approx 40 \%, \mathrm{MR} \approx 6: 1, \mathrm{~T}=160{ }^{\circ} \mathrm{C} ; \mathrm{T6}$ and $T 7:$ Cat. $\approx 4$ $\mathrm{g} \mathrm{L}^{-1}, \mathrm{MR} \approx 40: 1$ and $\mathrm{T}=180^{\circ} \mathrm{C}$. Lines are a guide for the eye.
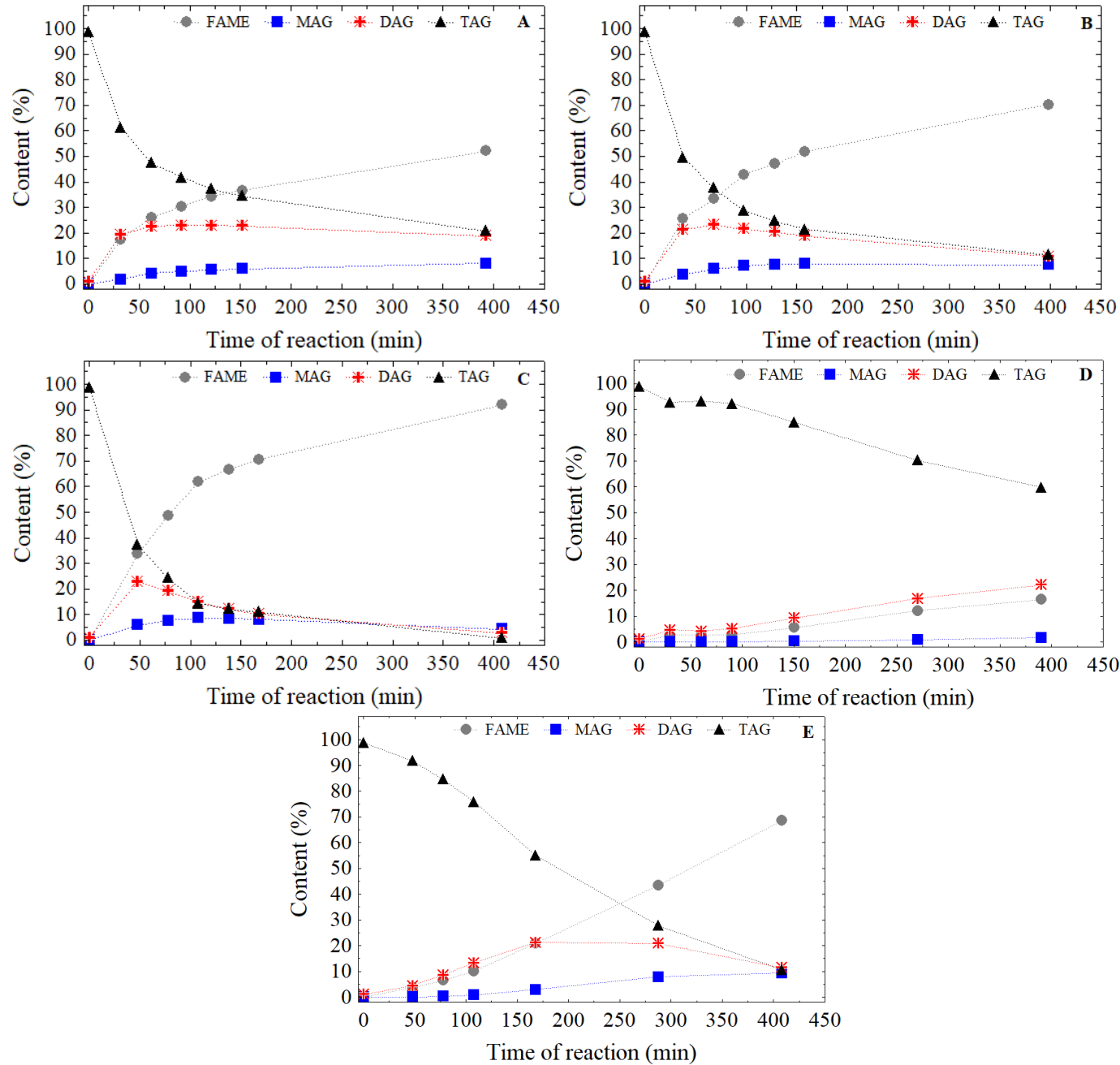

Figure A.4. Effects of both the presence of zinc monoglycerolate and the temperature in the transesterification of soybean oil with methanol. The symbols represent experimental data obtained for reactions (A) T1 (Cat. $=2.02 \%$, $\mathrm{MR}=50.67: 1$ and $\left.\mathrm{T}=140{ }^{\circ} \mathrm{C}\right),(\mathrm{B}) \mathrm{T} 2\left(\mathrm{Cat} .=2.00 \%, \mathrm{MR}=49.91: 1\right.$ and $\left.\mathrm{T}=160{ }^{\circ} \mathrm{C}\right),(\mathrm{C}) \mathrm{T} 3(\mathrm{Cat} .=2.02 \%$, $\mathrm{MR}=$ 50.21:1 and $\left.\mathrm{T}=180^{\circ} \mathrm{C}\right),(\mathrm{D}) \mathrm{T} 4\left(\right.$ Cat. $=0 \%, \mathrm{MR}=49.25: 1$ and $\left.\mathrm{T}=140{ }^{\circ} \mathrm{C}\right)$ and $(\mathrm{E}) \mathrm{T} 5($ Cat. $=0 \%, \mathrm{MR}=48.58: 1$ and $\left.\mathrm{T}=180^{\circ} \mathrm{C}\right)$. Dotted lines are a guide for the eye. 


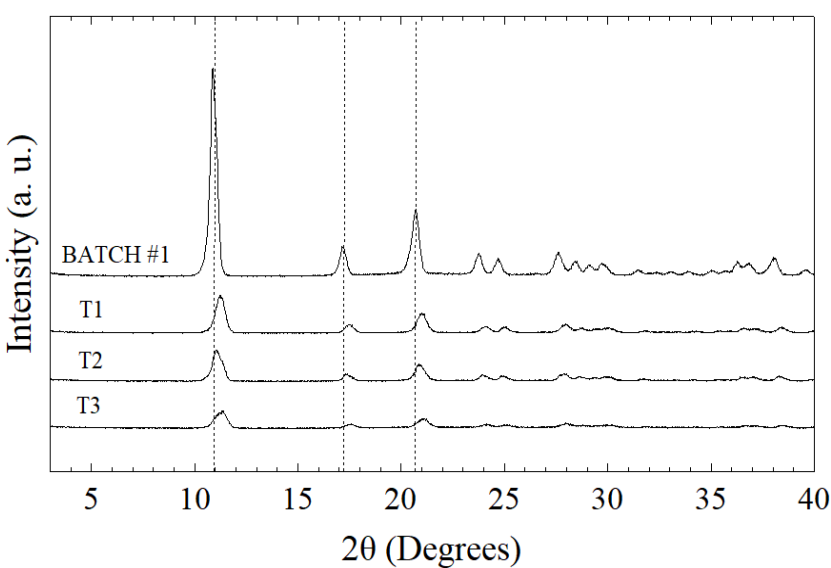

Figure A.5. Comparison of XRD analysis for zinc monoglycerolate before the reactions (batch \#1) and recovered after the reactions of methyl transesterification of soybean oil. Reaction conditions were: $\mathrm{T} 1:$ Cat. $=2.02 \%, \mathrm{MR}=50.67: 1$ and $\mathrm{T}=140$ ${ }^{\circ} \mathrm{C}, \mathrm{T} 2$ : Cat. $=2.00, \mathrm{MR}=49.91: 1$ and $\mathrm{T}=160{ }^{\circ} \mathrm{C}$, and T3: Cat. $=2.02, \mathrm{MR}=50.21: 1$ and $\mathrm{T}=180^{\circ} \mathrm{C}$.
Table A.1. Densities of the compounds used in this work as a function of temperature.

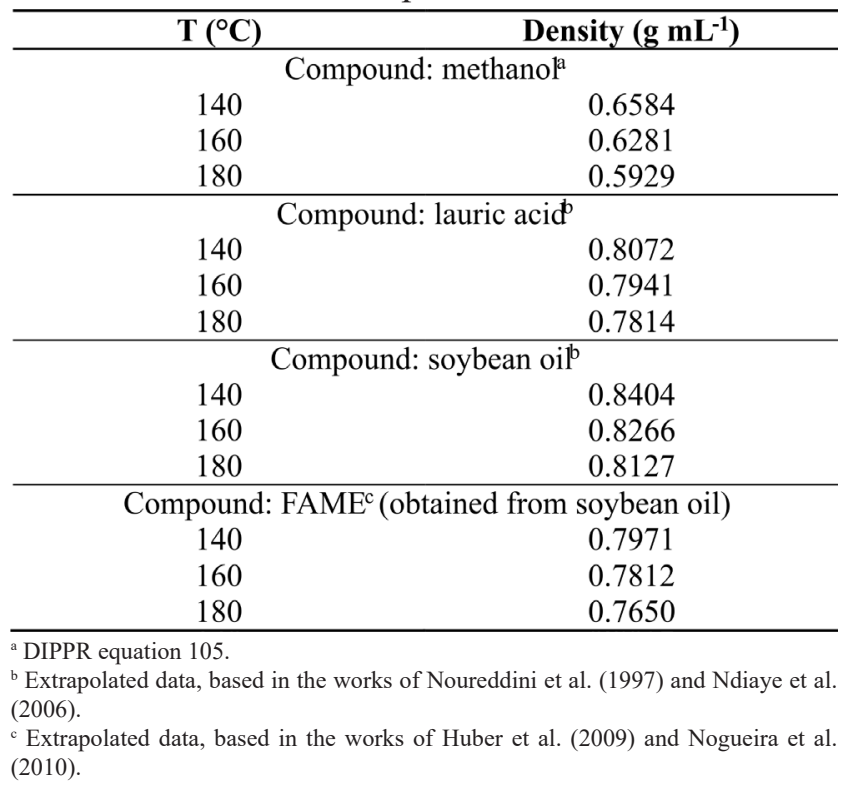


